Universidad de Lima

Facultad de Comunicación

Carrera de Comunicación

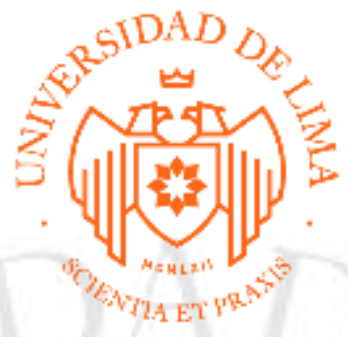

\title{
"LA DOCENCIA UNIVERSITARIA DESDE LOS OJOS DE UN
} COMUNICADOR"

Trabajo de Suficiencia Profesional para optar el Título Profesional de Licenciado en Comunicación

\section{Sandra Libia Bustamante Parodi}

Código 19952125

\section{Asesor}

Pedro Ortiz Bisso

$$
\text { Lima - Perú }
$$

Marzo de 2020 


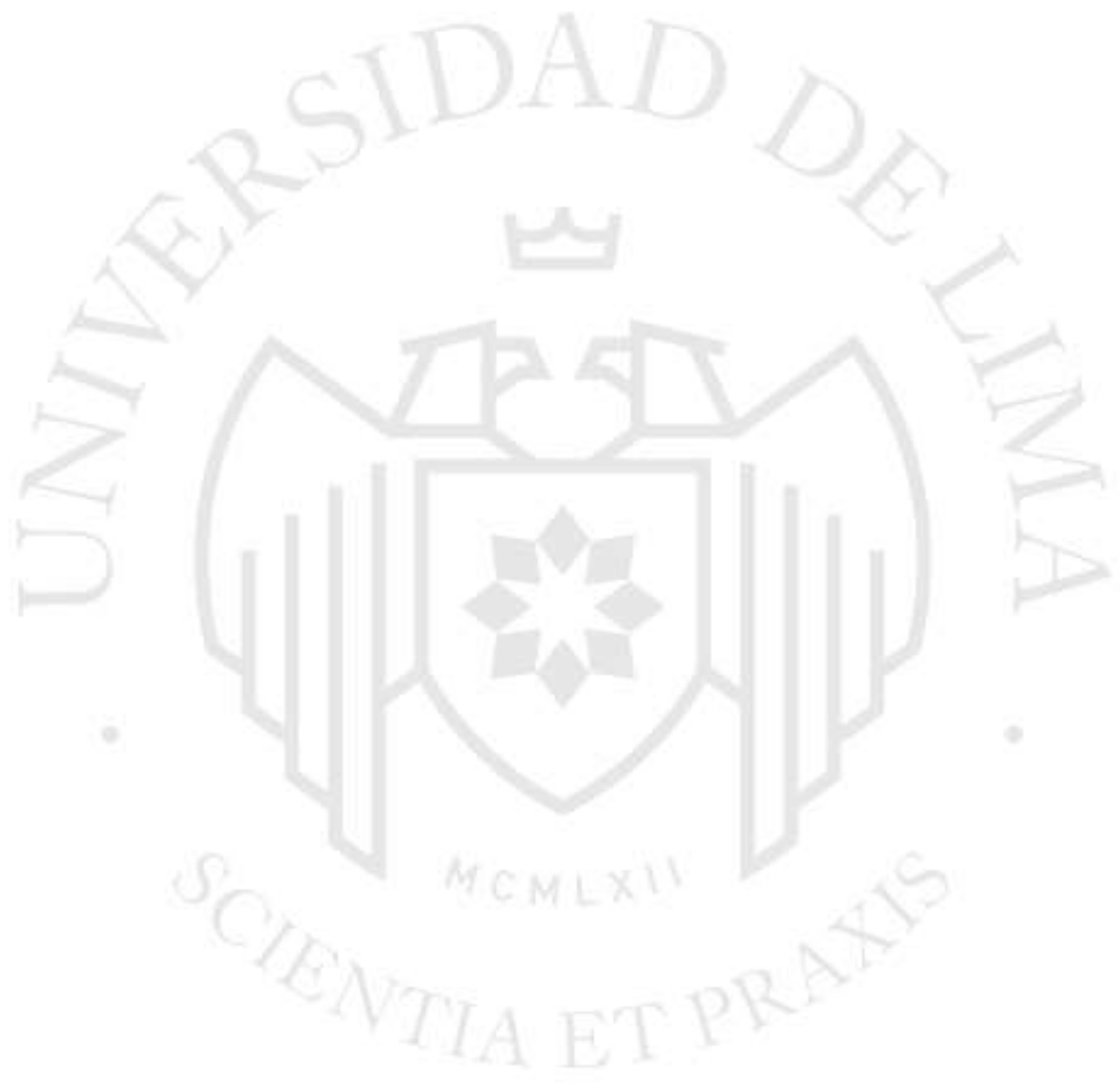




\section{LA DOCENCIA UNIVERSITARIA DESDE LOS OJOS DE UN COMUNICADOR}




\section{ÍNDICE}

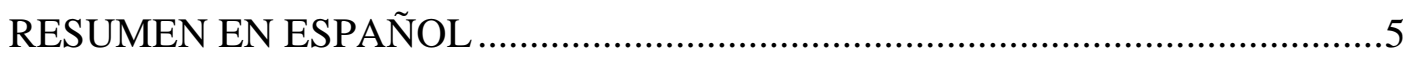

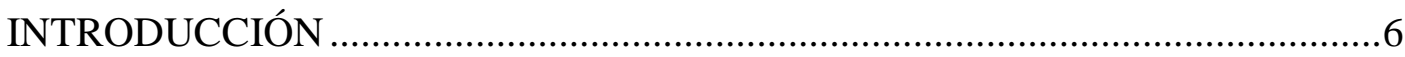

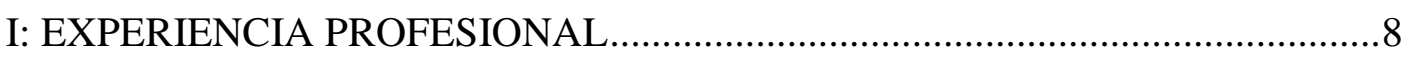

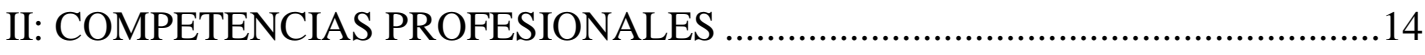

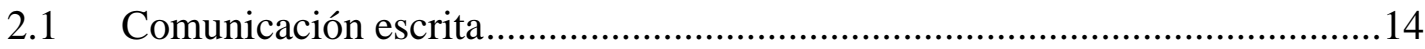

2.1.1 Una mirada al interior: el diario de clase ...................................................14

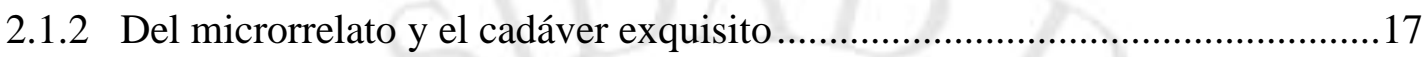

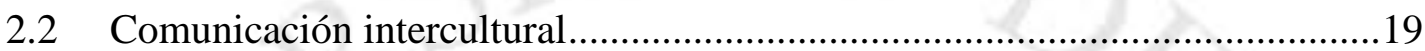

2.2.1 Entre la música y la educación: rap con sabor peruano ...................................19

2.2.2 Cuestión de fe: tiempo de fiestas patronales...............................................22

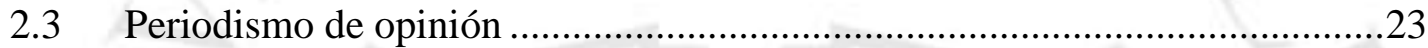

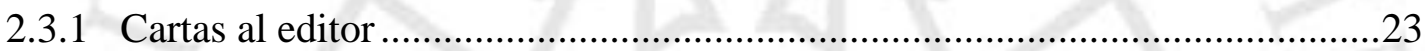

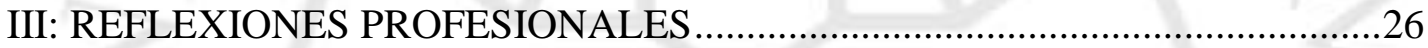

3.1 Sobre mi método de trabajo ....................................................................2

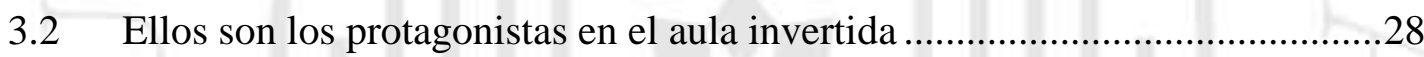

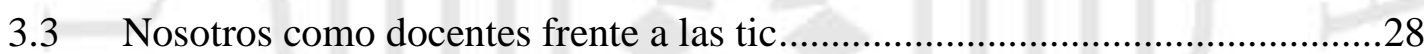

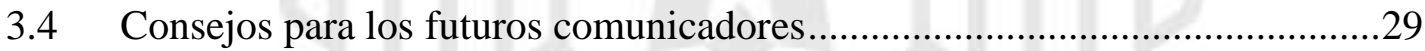

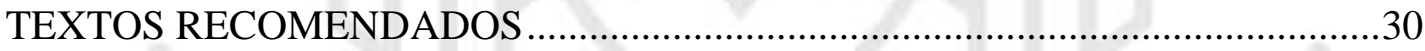

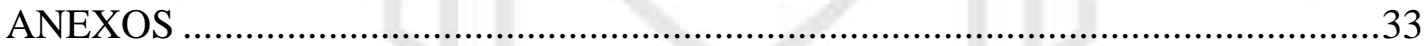

ANEXO 1: PORTADA E ÍNDICE DEL LIBRO: COMUNICACIÓN Y CAMBIO 34 ANEXO 2: TEXTOS PERIODÍSTICOS: DIARIO EXPRESO Y REVISTA

SOMMELIER

ANEXO 3: LISTADO GENERAL DE CAPACITACIONES, CURSOS,

DIPLOMADO, ENTRE OTROS

ANEXO 4: CURSO PERIODISMO DE OPINIÓN: COMPILACIÓN DE LO

PRODUCIDO EN EL SEMESTRE 


\section{RESUMEN EN ESPAÑOL}

Hoy en día, el comunicador integral debe desarrollar una visión holística de la carrera. Esta perspectiva compromete la suma no solo de herramientas comunicacionales que confluyen a partir de las nuevas tecnologías de la información y la comunicación, sino también de todas aquellas que corresponden al ámbito tradicional. En esta alianza, la docencia universitaria constituye un pilar fundamental como pieza de enroque para el desarrollo de habilidades blandas. El presente informe reflexiona sobre el aporte del comunicador a la docencia, la importancia de las emociones en la educación y finalmente, el rol del docente en un entorno digital, a través de algunos casos que exponen la construcción del diseño de aprendizaje.

\section{Palabras clave: docencia universitaria, comunicador, educación, habilidades} blandas, educación digital, educación emocional

\section{RESUMEN EN INGLÉS}

Nowadays, an integral communicator must develop a full view of the program. This perspective compromises not only communication tools that come together from the new information and the communication technologies, but also all those that correspond to the traditional field. Within this combination, University teaching is a fundamental pillar for soft skills development. This report reflects about the contribution of the communicator to teaching, the importance of emotions in education and finally, the teacher in a digital environment; through some cases that expose the construction of the learning design.

Keywords: university teaching, communicator, education, soft skills, digital education, emotional education 


\section{INTRODUCCIÓN}

La época universitaria ha sido, en buena cuenta, la que perfiló cada uno de los terrenos en los que me he desempeñado a lo largo de mi carrera profesional. La propia docencia -mi principal campo laboral y al cual me dedico desde hace ocho años- es el reflejo del legado de mis maestros: una clara manifestación de toda esa cuota gigantesca de libertad y seguridad que irradiaban, junto con una serie de conceptos que parecían no sólo iluminarnos sino también fragmentar nuestras mentes. Sumado a ello, un ligero porcentaje de afectividad para optimizar el proceso educativo.

Todo se inicia en la Universidad de Lima, a mediados de la década del 90, cuando ingresé a la Facultad de Ciencias de la Comunicación. Posteriormente, en 2006, hice la Maestría en Comunicaciones en la Pontificia Universidad Católica del Perú. Mi tesis data sobre una actividad que realicé durante mi infancia y adolescencia: escribir diarios personales. La titulé: Del diario íntimo al diario online. Construcción de identidad de los adolescentes limeños a través del espacio autobiográfico en internet: blog y redes sociales.

Desde el año 2012, estoy dedicada a la docencia y gestión universitaria. Actualmente, laboro en la Universidad San Ignacio de Loyola como docente a tiempo completo y en la Universidad de San Martín de Porres, como docente a tiempo parcial. Previamente, fui coordinadora de Comunicaciones y luego de Admisión en la Escuela de Posgrado de la Pontificia Universidad Católica del Perú.

He redactado en prensa en el diario Expreso (2002-2005) y en la revista Sommelier (2009-2010), así como para publicaciones e informes de Argos Productos Editoriales, Acción por los Niños, Save The Children y el libro Comunicación y Cambio $^{l}$, el cual reúne textos de egresados de la Maestría en Comunicaciones de la PUCP.

En el campo de la comunicación empresarial, ejercí la jefatura del área de Recursos Humanos de Tamatex S.A.C., empresa dedicada al rubro textil. Y casi de

\footnotetext{
${ }^{1}$ Anexos 1: Portada e índice del libro: Comunicación y Cambio.
} 
manera conjunta, hice con parte de mi familia un año de voluntariado en Olimpiadas Especiales, liderando un grupo de jóvenes con habilidades diferentes.

Las distintas direcciones que he tomado en mi vida profesional y académica han llevado el sello indiscutible de las comunicaciones. Por esa razón, sigo tratando de imprimirle a la docencia aquella cualidad tan particular que tiene el comunicador: ser un facilitador del mensaje (valerse de los medios de comunicación para que sea recibido de la mejor manera), darle un peso adecuado a lo afectivo, estimular empáticamente los contenidos, propiciar la colaboración entre pares y abrir camino al pensamiento crítico. 


\section{I: EXPERIENCIA PROFESIONAL}

Mi quehacer docente y cada una de los puestos que he ocupado en estos 19 años, encuentran su punto de arranque en cursos y experiencias que tuve en el pregrado. Creo importante recalcar que mi especialidad en la Facultad de Comunicaciones fue el periodismo. Inicié mi vida laboral en la sección Cultural del diario Expreso (2001-2005)2. Mi jefe fue el doctor Ismael Pinto Vargas ${ }^{3}$, quien tuvo la paciencia de complementar lo aprendido en las aulas con lecciones que hasta hoy recuerdo: cómo manejarse en una entrevista, cómo hacer una buena pauta de preguntas, no escribir desde la crítica negativa y otras más. Él era amigo del "joven Bryce” (como llamaba al reconocido escritor, Alfredo Bryce Echenique), le hacía bromas por el día de los inocentes a Jaime Bayly, tenía incontables historias sobre LAS (Luis Alberto Sánchez) y una especial sabiduría para calmar a Martha Hildebrandt o consolar a una triste Blanca Varela. Me defendió a ultranza cuando alguien trató de ningunearme por ser una novata en las lides del periodismo. Me quitó el habla durante días por no cubrir a su gusto mi encuentro con Mario Vargas Llosa en Italia. Me contó todas las historias con Gabriel García Márquez y Julio Ramón Ribeyro. Y, en un gesto que atesoro, me presentó a su familia, con la que desde entonces comparto el almuerzo casi todos los domingos en una mesa que hace un par de años dejó de gozar de sus inagotables ocurrencias.

Fueron años tan maravillosos como agotadores. Cuando se trabaja en prensa no existen cumpleaños, navidades ni feriados. Confieso que llegué a cansarme. Sentía que me estaba repitiendo en las notas, que debía explorar otros caminos. Sólo retomé el periodismo años después en la Revista Sommelier (2009-2010). Luego de Expreso, tomé un año sabático y me hice voluntaria en Olimpiadas Especiales (2005-2006). Para ser honesta, tenía muchos reparos de conocer a los atletas. Lo pienso en retrospectiva y me parece absurdo, pero así fue.

Las primeras semanas fueron duras. Los padres detestaban ese empoderamiento que buscábamos darle a sus hijos. Creo que tenían miedo de verlos crecer. Ellos los

\footnotetext{
${ }^{2}$ Anexos 2: Textos periodísticos: diario Expreso y revista Sommelier.

${ }^{3}$ Ismael Pinto Vargas fue secretario de la Academia Peruana de la Lengua y miembro de la Academia de la Historia del Perú, además de autor de varios libros y un centenar de artículos periodísticos.
} 
concebían como niños y la gran mayoría pasaba los 20 años. Lo cierto es que eran campeones adultos y debían convencerse de ello. Los acompañamos a sus entrenamientos, a las competencias, hacíamos lo que ahora llaman coaching, íbamos a las colectas. Se hicieron fuertes, se volvieron seguros.

Ahora bien, hacia el 2006 tocaba asumir un reto que parecía ineludible: el negocio familiar, Tamatex S.A.C. Era una tintorería industrial que negociaba con el emporio de Gamarra. Durante años había postergado la decisión de integrar la planilla de nuestra empresa. Necesitaba generar ingresos rápidamente y las puertas se abrieron de manera sencilla. Ocupé el cargo de Jefa de Recursos Humanos frente a un personal de cien obreros que no veían bien a una mujer cumpliendo ese tipo de responsabilidades. Fue difícil pero se lograron mejoras en el cumplimiento de las políticas y en la comunicación interna. Nos pusimos en regla con el Ministerio de Trabajo, ofrecimos talleres de capacitación, de digitalización de los pagos, entre otros (2006-2011).

Pronto me llegaron propuestas para realizar trabajos de redacción y consultoría. Nathalie Hendrickx y Augusto Tamayo me pidieron sumarme a Argos Productos Editoriales (2011-2013). Sin dudarlo, acepté. Era el momento de regresar a escribir, hacer un poco de relaciones públicas y producción. Redactamos parte de las memorias de la Universidad de Lima, que creo no llegaron a ver la luz. Posteriormente, logramos hacer dos libros: Tradición y Modernidad: San Isidro y Distrito de San Miguel.

Simultáneamente, Acción por los Niños me pidió editar el Manual para Periodistas y Comunicadores sobre el Tratamiento de Noticias de Violencia Familiar y, Save The Children -a cargo de Teresa Carpio- me encargó los siguientes proyectos de consultoría en comunicaciones:

- La organización, difusión y seguimiento del Foro Binacional "Protección a la Infancia: Movilidad Humana y trata de personas Perú - Ecuador”. Julio 2013.

- La organización, difusión y seguimiento del Taller Internacional "El abuso sexual, pautas para una efectiva intervención”. Julio 2013.

- La gestión en medios del Proyecto Combatiendo la explotación sexual y laboral de niños, niñas y adolescentes en la minería informal de Madre de Dios y Cusco. Enero 2012. 
- Organización, difusión y seguimiento del Foro Nacional "Retos y Desafíos Comunes para Garantizar los Derechos de la Primera Infancia”. Agosto 2011.

- Organización, difusión y seguimiento del Caso de Corrupción de Magistrados en Huánuco. Diciembre 2011.

A inicios de 2012, Hendrickx me hizo saber que necesitaban una docente a tiempo parcial en la Universidad San Ignacio de Loyola. No transcurrió más de un mes cuando me ofrecieron la coordinación de eventos especiales en la carrera de Comunicaciones. El nuevo director de aquel momento, doctor Anthony Spencer, buscaba que la carrera fuera querida por los estudiantes, como lo era la Universidad de Lima para mí. Él buscaba cambios radicales: movernos en redes sociales, hacer charlas vivenciales, ferias de carrera, ir a colegios, realizar visitas guiadas, entrevistas a los postulantes a la carrera. Además, buscaba darle mucha libertad a los alumnos y nuevos bríos a todo, lo que implicaba, entre otras cosas, crear una sala de cine y equipar la cabina de radio. Todo eso se logró. Y más. Se organizó una suerte de "Comunicarte" al cual llamamos "Comunícate"4, emulando el evento que existía cuando era alumna de la Facultad de Comunicaciones en la Universidad de Lima.

En el lado académico, logré finalmente uno de los sueños que tenía durante años: ser docente. Tuve a mi cargo los cursos de Comunicación Escrita, Redacción Periodística y Periodismo Escrito. Todos ellos dictados bajo el enfoque de formación por competencias.

Todo el equipo de Spencer estuvo solo algo más de un año (2012-2013). Una nueva cabeza tomó la posta (Úrsula Vallejo, mi jefa en la actualidad). Luego de un par de ciclos (2014-2017), regresé a la USIL para dictar Introduction to Public Speaking, un curso de coaching en el Programa de Doble Grado (DG) con San Ignacio University de Maimi, lo que me valdría el aprecio de Claudia Rodríguez, vicepresidenta de Relaciones Internacionales del Center for Global Education y del propio DG USIL. Resultó una experiencia diferente con estudiantes que tenían pocas habilidades en materia de comunicación oral. Se lograron muy buenos resultados y experiencias para recordar.

\footnotetext{
${ }^{4}$ Primera Semana de Comunicaciones Comunícate https://youtu.be/weWsK4qOgKQ
} 
En 2013, ingresé a laborar en la Escuela de Posgrado de la Pontificia Universidad Católica del Perú. Durante tres años me encargué de la comunicación externa de la escuela. Se logró difundir la oferta educativa de posgrado hacia los interesados a través de la ejecución y el manejo de una nueva base de datos, la cual se construyó a partir de mi presencia en ferias de posgrado en Ecuador (un buen mercado para este tipo de programas), Bolivia y en el interior del país (Arequipa y Trujillo, básicamente).

De la misma manera, la base se complementó con eventos académicos (charlas, seminarios, etc.), contacto con interesados, atención a visitantes en el campus PUCP, entre otras actividades. El trabajo de marketing fue arduo y directo con los potenciales postulantes. Mis funciones derivaron en el nuevo puesto de coordinadora de Admisión (2016-2017), cuya función consistía en planificar y gestionar este proceso, así como proponer proyectos especiales para mejorar su área de gestión académica de la Escuela de Posgrado PUCP. También trabajé en la capacitación del personal a cargo de la atención y orientación integral del postulante, uno de los puntos clave y en los que incidí durante mi paso por esta casa de estudios ${ }^{5}$.

En 2017, Úrsula Vallejo, actual directora de la carrera de Comunicaciones USIL, me llamó para ofrecerme una plaza como docente a tiempo completo (2017 hasta la fecha). Acepté feliz. Volver a la docencia y a trabajar en contacto directo con estudiantes era un cambio necesario. He dictado una amplia variedad de cursos en modalidad virtual: Historia de la Comunicación, Psicología de la Comunicación, Comunicación y Globalización, Ética y Comunicación y Comunicación Intercultural ${ }^{6}$. Y otros dos en modalidad presencial: Comunicación Escrita I y II. Tengo a mi cargo también las entrevistas de admisión a la carrera, la asesoría y jurado de tesis. Cabe resaltar que, como profesora universitaria, he recibido una serie de capacitaciones y cursos de actualización cada año ${ }^{7}$, entre ellos el Diplomado en TIC aplicadas a la Educación (USIL, 2019).

\footnotetext{
${ }^{5}$ En el ínterin, asesoré la tesis: El marketing experiencial en Vive PUCP - Tesis para optar por el grado de Magíster en Política y Gestión Universitaria por la Pontificia Universidad Católica del Perú (2017) de Miyela Armas Marquina URI: http://hdl.handle.net/20.500.12404/7941

${ }^{6} \mathrm{Mi}$ canal en YouTube: https://goo.gl/eEo4u3

${ }^{7}$ Anexos 3: Listado general de capacitaciones, cursos y diplomado
} 
Como principal logro, destaco la empatía con los estudiantes, el buen clima de nuestra carrera y el promedio obtenido en el resultado de la evaluación de los alumnos: 18.96/20. Me alegra mencionar que en 2018, junto con otros colegas, fui condecorada como la mejor docente de la carrera por una labor destacada ${ }^{8}$. Asimismo, tuve el honor de ser escogida para presentar, en el marco de la Cátedra Vargas Llosa, a mi periodista favorita: Leila Guerriero9 .

Debo confesar que para mí el aula es un espacio de abstracción del mundo exterior. En él se logra dejar de lado cualquier distracción que impida conseguir mi principal objetivo: que los estudiantes aprendan de manera lúdica. Busco que perciban que el proceso de aprendizaje no tiene por qué estar desprovisto de emoción. Muy por el contrario, cada sesión debe moverse entre la eficacia y la afectividad, dejando de lado lo impersonal.

Tanto en la USIL como en la Universidad de San Martín de Porres (2019 hasta la fecha), donde dicto a tiempo parcial el curso de Periodismo de Opinión, trato de promover relaciones positivas a nivel afectivo con mis alumnos. He comprobado que los estudiantes, en un entorno de esa naturaleza, se involucran más en su propio aprendizaje, además de adquirir una serie de competencias blandas, más allá de lo meramente cognitivo. Brindar la importancia debida a la inteligencia emocional deber ser parte ineludible de cualquier método de enseñanza que aspire a ser eficaz. Lamentablemente, estamos lejos de ello.

A fines de 2019, perseguí tener otro tipo de conocimiento. Decidí participar en un "Hackaton", una suerte de maratón digital que reta a los participantes a crear y desarrollar un proyecto específico multidisciplinario. Obtuve el segundo lugar en el Hackaton Mujeres hackeando por mujeres: equidad de género, organizado por The Blockchain Challenge $(2019)^{10}$. Finalmente, me convocaron a participar en la evaluación externa del

\footnotetext{
8 Mejor docente de la carrera de Comunicaciones. Universidad San Ignacio de Loyola. (2018). http://www.usil.edu.pe/noticias/docentes-usil-fueron-reconocidos-su-destacada-labor

9 Reconocida periodista argentina Leila Guerriero brindó charla en USIL https://www.usillife.pe/noticias/leila-guerriero-charla/

${ }^{10}$ Proyecto: Cartilla digital de vacunación (Vccsys). https://bit.ly/2DqejYE Premio: Beca para participar en el Talent Land.
} 
concurso Programa de Diplomado en Divulgación Científica 2019-01, propuesto por el CONCYTEC y financiado a través del FONDECYT ${ }^{11}$.

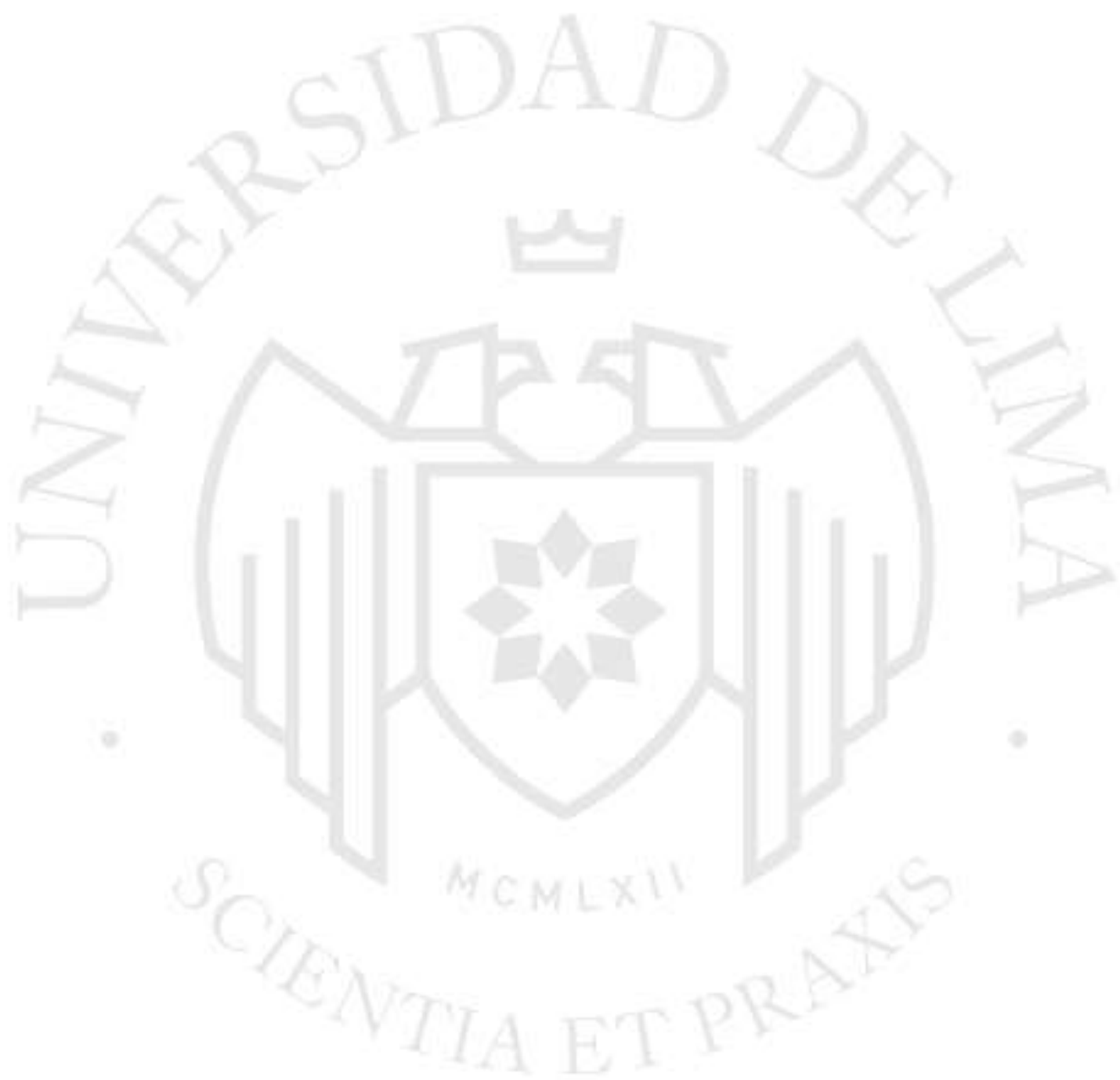

${ }^{11}$ Adjunto constancia en Anexos 3. 


\section{II: COMPETENCIAS PROFESIONALES}

La docencia universitaria desde los ojos de un comunicador

El rol de comunicador no es ajeno al de docente. Todo lo contrario, lo fortalece y dota de competencias en materia de relación interpersonal e intragrupal, así como herramientas tecnológicas cercanas al mundo de los estudiantes, que lo ayudan a cumplir su misión con mayor eficiencia.

Los casos descritos a continuación forman parte de los once cursos - presenciales y virtuales- que he dictado a lo largo de los últimos ocho años. A través de ellos, he buscado trabajar con cada una de las instancias del proceso comunicativo en el escenario de la educación universitaria, desarrollando habilidades blandas en los estudiantes (receptores), movilizando emociones en el docente (emisor) y buscando garantizar el aporte que los contenidos (mensajes), dinámicas y metodologías (canales) brindan a los participantes. El objetivo final ha sido siempre uno solo: optimizar el proceso pedagógico.

\subsection{Comunicación Escrita}

\subsubsection{Una mirada al interior: el diario de clase}

\section{- Objetivos}

Primer objetivo:

Autoevaluar los progresos en torno a la escritura a lo largo del curso.

El proyecto integrador permite que los estudiantes puedan tener un registro personal de su desenvolvimiento en clase y que los docentes adquieran una herramienta poderosa para la reflexión y evaluación continua.

Segundo objetivo:

Facilitar el desarrollo de pensamiento crítico, introspección, observación y auto observación.

Se busca que los estudiantes reflexionen de manera crítica, aprendan a auto observarse, a conectar lo subjetivo con lo objetivo y a ser conscientes de los patrones de comportamiento que predominan en su vida y en la de los demás. 


\section{Tercer objetivo}

Generar autoestima y empoderamiento en los estudiantes.

A través de la escritura creativa de carácter lúdico, se busca romper con la idea que sólo pueden escribir los más destacados literatos. Todos pueden hacerlo y encontrar en este acto creativo la posibilidad de analizarse y librar ciertos demonios con la finalidad de empoderarse y quererse a sí mismos.

\section{- Descripción del caso}

No es casualidad que la selección que he hecho coincida con los cursos que más me gusta dictar y a la vez tenga una correspondencia directa con aquellos que fueron mis favoritos en los años de estudiante universitaria. Comunicación Escrita en la Universidad de Lima llevaba el nombre de Expresión Escrita. Recuerdo este taller como un espacio para pensar, sentir y escribir. Las técnicas aplicadas (escribir a partir del final, ubicarse en la voz de un narrador diferente, describir con originalidad, entre otras) conjugaban perfectamente con una lectura diferente en cada semana.

Si bien es cierto, ambas profesoras del curso obtuvimos un sílabo base, el coordinador académico de la carrera, Ricardo Ramos Jaramillo, nos dio total libertad para hacer los cambios necesarios. Así, con Michelle Zumarán se concibió un taller con trabajos semanales de redacción basados en distintos textos.

El proyecto integrador, denominado diario de clase, toma fuerza a partir de los estudios de posgrado de ambas docentes. Ella tiene un master en Creative Writing de la New York University (NYU) y yo, en mis estudios de maestría en la PUCP, desarrollé el tema de los diarios íntimos como forma de liberación y de conocerse a uno mismo y a los demás. Sumado a esto, las publicaciones: El diario de clase... Un diario para la vida de Catarina Goldoni (Goldoni, 1996) y El diario personal del alumnado como técnica de investigación en Educación Física de Álvaro Sicilia (Sicilia, 1999), reforzaron nuestra propuesta.

Este es el examen final del curso y es de carácter grupal. Se entrega de manera física, previa exposición de todos los trabajos en clase. En el proceso de elaboración, se recomienda a los estudiantes que tengan un cuaderno y este rote de compañero a 
compañero, o que sea hecho en hojas individuales que más adelante se agrupen. Corresponde a ellos establecer una rutina de tiempo para la redacción. Las docentes recomendamos que sea a razón de dos veces por semana.

Sobre el desarrollo de la parte narrativa, para darles pie a una redacción fluida, formulamos una serie de interrogantes: ¿Qué he conseguido hoy? ¿Qué he aprendido? ¿Cuáles son mis proyectos? ¿Tengo problemas con respecto a alguien o algo? Del mismo modo, tienen la posibilidad de agregar canciones, relatos breves o poemas creados por ellos mismos. Igualmente, pueden opinar y reflexionar sobre películas, obras o conciertos. También incluir fragmentos de cuentos o noticias importantes que hayan escuchado o leído, más allá de las experiencias del día a día. Finalmente, pueden regresar a los primeros textos y autocriticarse.

\section{- Resultados obtenidos}

Acercamiento del docente a la vida de los alumnos, a sus cuestionamientos. La viabilidad de reorientar el proceso de enseñanza. De igual manera, fomentar la reflexión en el profesor y el estudiante.

Democratización de la escritura en manos de alumnos universitarios con la finalidad de aumentar su autoconfianza y empoderamiento.

Desarrollo de la creatividad.

Desarrollo del proceso de introspección y posibilidad de brindar importancia a las emociones.

Capacidad de organización para trabajar en equipos.

- Materiales producidos

Diario de Clase 1: Diana Hurtado y Gabriela Pérez https://1drv.ms/u/s!AvD2xVVJUZAUv0bzt1dm3q7oRh8Y?e=WKGEKj

Diario de Clase 2: Sanny Carrillo, Joel Bernal, Angelo Villanueva y Willy Espinoza

https://1drv.ms/u/s!AvD2xVVJUZAUv0VVxUMI18OZNxSP?e=sGy6LE Diario de Clase 3: Arlyn Chinchay https://1drv.ms/u/s!AvD2xVVJUZAUv17U3ADieK4smtPJ?e=4sAmLX 


\subsubsection{Del microrrelato y el cadáver exquisito}

\section{- Objetivos}

\section{Primer objetivo}

Desarrollo de la creatividad.

Conseguir que los estudiantes sientan mayor apego a ejercicios novedosos, originales que pongan en juego su creatividad. Finalmente, estimular al docente y al alumno.

\section{Segundo objetivo}

Desarrollo de la agilidad mental e imaginación.

Junto con la agilidad mental para la creación de ambos tipos de textos breves, se busca rescatar la espontaneidad en el acto de escribir.

\section{Tercer objetivo}

Fortalecer la autoestima y empoderar al alumnado.

A través de la redacción creativa, se busca que la expresión escrita esté al alcance de todos y que no solo sea una actividad que disfruten, sino también de una de la que puedan enorgullecerse.

\section{- Descripción del caso}

Después de algún tiempo de tratar estos temas de manera individual, decidí que el microrrelato ${ }^{12}$ y el cadáver exquisito ${ }^{13}$, hacían una buena dupla en tanto ambos cumplían con los mismos objetivos.

Mis principales referencias para trabajar este caso fueron: Seis actividades de escritura creativa basadas en objetos de Miguel Salas (Salas Díaz, 2011), La lectura y la escritura creativa sanan las heridas del alumnado (La lectura y la escritura creativa sanan las heridas del alumnado, 2015), Antología: El Cadáver Exquisito como fin

\footnotetext{
${ }^{12}$ El microrrelato, como su nombre lo indica, es una construcción literaria de carácter ficcional muy breve. El título cobra gran importancia en este tipo de texto al igual que un final, súbitamente inesperado. La elipsis es una de las principales figuras literarias utilizadas en el microrrelato.

${ }^{13}$ Debo aceptar que muchas veces he recibido críticas de algunos docentes por trabajar con actividades de escritura creativa basada en objetos. El cadáver exquisito no está exento de ellas. Este es una técnica de escritura utilizada por los surrealistas a inicios del siglo XX. Se centra en continuar un relato obedeciendo a la última palabra escrita por el que antecede en la redacción. Puede también ser cerrado y guiados por una sola temática.
} 
(Perezchica, 2008) y Microrrelatos: grandes placeres de la pequeña literatura (PérezBustamante Mourier, 2005).

En esta actividad, lo solicitado era realizar un microtexto (no más de 50 palabras) que gire en torno a una moneda de cinco centavos. Cada alumno trabajaba en un pequeño papel independiente el cual luego era unido al de sus compañeros, haciéndose un gran acordeón de relatos anónimos. Mientras ellos escribían, se proyectaba en el aula un fragmento del documental experimental Mysterious Object at Noon, el cadáver exquisito visual de Apichatpong Weerasethakul. Asimismo, se mostraban distintos ejemplos de microtextos en torno al tema -trabajos de sus compañeros en otros ciclos- y a otros de Augusto Monterroso, Gabriel García Márquez, etc. Al final de la clase, se leían todos los trabajos.

Cabe resaltar que, dependiendo del tiempo y si estaba abierta la convocatoria de concursos, los estudiantes enviaban sus escritos al certamen de microrrelatos de Signo Editores $^{14}$.

\section{- Resultados obtenidos}

Fortalecimiento de la autoestima a través de:

a) La visibilización de la producción de los microrrelatos de los estudiantes de la carrera de Comunicaciones. Curso: Comunicación Escrita. Página de Instagram: Relatos de Cinco Centavos ${ }^{15}$.

b) La participación de los estudiantes del curso Comunicación Escrita en el certamen de microrrelatos de Signo Editores. Varios de ellos quedaron preseleccionados y la emoción que supuso fue altamente gratificante (no sólo para ellos).

Desarrollo de la imaginación y la creatividad, además de un mayor gusto por la escritura a través de actividades de escritura creativa.

Reflexión en torno a la importancia de la producción colectiva.

\footnotetext{
${ }^{14}$ Certamen de Microrrelatos de Signo Editores https://www.signoeditores.es/certamen-de-microrrelatossigno-editores/

${ }^{15}$ Página de Instagram: Relatos de Cinco Centavos https://www.instagram.com/relatosdecincocentavos/
} 


\section{- Materiales producidos}

Relatos de cinco centavos anónimos en Instagram de los estudiantes del curso Comunicación Escrita de la carrera de Comunicaciones USIL:

Texto 1: El tesoro de la suerte https://www.instagram.com/p/BzvT5TIBXGe/?igshid=gyk3xu5k2mcu

Texto 2: El chicle en la suela https://www.instagram.com/p/BzGBZ5Qhk6K/?igshid=1qlsfcuw3kd3m

Texto 3: La moneda mágica

https://www.instagram.com/p/BzQbt6JhKBI/?igshid=1msz7bwtfhll0

Texto 4: No existe el olvido

https://www.instagram.com/p/B5DIF6B1Em5/?igshid=s4nrpt5yxic6

Texto 5: Metros y metros de microrrelatos.

https://www.instagram.com/p/Bzx32TXh1Fj/?igshid=1en6s5uqre282

Certamen de Microrrelatos de Signo Editores. Participación de los alumnos:

Héctor Astorayme, Gianira Gamboa, Mauro Orbegoso, Diego Sotomayor, Romina

Maldonado y Michael Velásquez

https://1drv.ms/u/s!AvD2xVVJUZAUv2L8Oj98FowemHTn?e=veSaAW

\subsection{Comunicación Intercultural}

\subsubsection{Entre la música y la educación: rap con sabor peruano}

\section{- Objetivos}

Primer objetivo

A través de la creación de un rap, el estudiante universitario analiza y aprecia su propia identidad cultural.

\section{Segundo objetivo}

El alumno tendrá los elementos necesarios para comunicar y producir contenidos que funcionen eficazmente para acortar las diferencias sociales.

\section{- Descripción del caso}

Comunicación Intercultural (CI) es un curso en la modalidad e-learning de la carrera de Comunicaciones USIL. Es necesario mencionar que CI fue dictado presencialmente hasta el ciclo 2018-1. Cuando pasó a mi cargo, no sólo se tuvo que digitalizar todo el 
material ${ }^{16}$ sino que también debía ser una propuesta que pudiera captar la atención de los alumnos, quienes venían desanimados con la virtualización creciente de cursos en la universidad.

Es así como un pequeño grupo de psicólogos y educadores orientaron a algunos docentes para poder optimizar nuestro trabajo a través del uso de las TIC. Dentro de las sugerencias se barajó la utilización de distintas app para no incurrir en tareas convencionales: Pixton (elaboración de comics a partir de una lectura o charla), generador de pupiletras, Animoto (creación de videos), Lucidchart (para hacer mapas conceptuales), Piktochart (infografías), Podbean (podcast) o Meme Generator Free (app para crear memes), entre otras.

Sin embargo, no todas ellas gozan de la preferencia del alumnado. Por el contrario, uno de los ejercicios que concitaba su mayor interés era la creación de un rap. Este nació a partir de las siguientes referencias:

- El gusto creciente de mis alumnos por los eventos de freestyle rap.

- La actitud contestataria de los jóvenes unida a las ganas de expresar su descontento con el sistema.

- En un exceso de idealismo, sumarnos a la propuesta del rapero español El Chojin (Chojín, 2011): Identidad, campaña mundial contra el racismo y discriminación (en la versión peruana se han unido y apoyado 11 músicos nacionales (Chojín \& Enece, Rap vs Racismo Perú, 2018)).

- El rap de la Educación 2.0. Propuesta de la Fundación Telefónica España (Telefónica, 2012) para darle voz a los jóvenes y que estos puedan expresar sus ideas a través de la música, específicamente, el rap.

- La tesis de María Fernanda Silva Salgado: La universidad de la calle y de la vida: El Hip Hop como experiencia educativa (Silva Salgado, 2016).

El nombre de la tarea grupal era Rap con sabor peruano y las indicaciones para elaborar el rap recogía los conceptos vistos en clase (que aluda a cuestiones relacionadas a nuestra identidad cultural: racismo, segregación, ¿cómo podríamos integrarnos?, etc.). El video debía durar de 2 a 3 minutos.

\footnotetext{
${ }^{16}$ Tuvimos además que migrar a la plataforma digital Canvas.
} 
Posteriormente, con la finalidad de que los alumnos visibilicen sus trabajos y conozcan las letras hechas por los demás, sometimos los videos a votación a través de la herramienta foros de discusión en Canvas. Cada grupo aportó sus valoraciones y el rap con mejor puntaje exoneró la práctica siguiente.

\section{- Resultados obtenidos}

A través de dos entrevistas ${ }^{17}$ pude recoger las palabras de dos de mis estudiantes con quienes coincido. Según Cynthia Espinoza, "la creación del rap fue una tarea muy novedosa a comparación de otros cursos que he tenido en la universidad. Nunca me habían enviado a hacer una tarea donde mezcle el contenido teórico con la creatividad de manera grupal (...). Esto fue como romper con un esquema académico (...). El tema de los foros nos permite tener contacto con la profesora. Es una actividad que motiva a que trabajemos de una manera creativa e integrada".

Por otro lado, Diana Hurtado comentó que “escribir la canción porque quería crear algo que esté lleno de contenido (...), esto hace que aumente nuestra creatividad incluso en la edición".

En conclusión, como resultados obtenidos tenemos un acercamiento considerable a realizar un llamado de rechazo al racismo y a la discriminación, a través de un ritmo con llegada a los estudiantes. Asimismo, se rompieron esquemas académicos en los cursos teóricos para relacionar a los alumnos con las TIC (a través de los foros, app, redes sociales, etc.) y, finalmente, se buscó un aumento de la creatividad.

\section{- Materiales producidos}

Rap 1: Hipocresía https://youtu.be/LbSH-krKbtQ Integrantes: María Elena Barbeyto, Luciana Barturén, Cynthia Espinoza, Diana Hurtado, Gabriela Pérez y Katherine Saenz. Rap 2: Levanta el puño https://youtu.be/JeDU1fVUnSM Integrantes: Catalina Morales, María José Rodríguez, Breisner Camacho, Brian Paulino y Rodrigo Mantari.

${ }^{17}$ Cynthia Espinoza: Comentarios sobre los resultados obtenidos a través de Rap con sabor peruano https://youtu.be/jjb6hnpe8n0

Diana Hurtado: Comentarios sobre los resultados obtenidos a través de Rap con sabor peruano https://youtu.be/RTHh 59FBdM 


\subsubsection{Cuestión de fe: tiempo de fiestas patronales}

\section{- Objetivos}

\section{Primer objetivo}

La conexión del estudiante con una festividad típica peruana.

Se busca que el alumno no sólo consiga un acercamiento a nuestro sincretismo religioso sino que también pueda reflexionar en torno a sus vivencias, contrastándolas con la teoría. Al mismo tiempo, poder socializar y relacionarse con los asistentes, conocer sus impresiones y ser partícipes del proceso festivo.

\section{- Descripción del caso}

Esta tarea representaba el examen final y debía ser un reportaje sobre una fiesta patronal. Era una actividad muy similar a la que realicé en épocas universitarias en los cursos de Liuba Kogan y Gina Gogin (Identidad e Interacción Social y Diseño y Análisis Cualitativo, respectivamente). Tiempo de duración: 7 a 9 minutos. Era anunciado tanto virtual como presencialmente al inicio de clase y la presentación se realizaba en dos etapas de manera virtual (en un foro en la plataforma virtual Canvas) durante la última semana del curso:

- A través de una discusión en torno al sincretismo religioso, basándose en las experiencias vividas (de 0 a 5 puntos).

- El producto final (0 a 15 puntos).

La participación era de todo el grupo y de manera activa en la festividad: debían establecer contacto previamente con alguien representativo de la festividad con la finalidad de que se formularan algunas preguntas. Asimismo, durante la fiesta, tenían que conversar con los comensales y comentar sus impresiones. Recibieron dos asesorías (una virtual y otra presencial) previas a la entrega del examen con la finalidad de levantar observaciones de corte teórico y audiovisual. Cabe resaltar un dato curioso: aunque hay quienes escogen clubes departamentales o locales en los conos de Lima para llevar a cabo la grabación, no faltan alumnos que buscan salir de Lima. El curso es visto como una oportunidad para vivir la experiencia de viajar en grupo.

Mis principales referencias fueron extraídas de los textos: Fiestas Tradicionales Popular del Perú (García \& Tacuri, 2006) y La gestión de la diversidad religiosa en el 
Perú (Calvi del Risco, 2015); así como de la entrevista realizada a la socióloga Catalina Romero (Miguel, 2017) por el diario El Comercio.

\section{- Resultados obtenidos}

Rescato que mis estudiantes, gracias al trabajo de campo, hayan logrado reflexionar sobre conceptos relacionados a la comunicación frente a situaciones de diversidad cultural y religiosa ${ }^{18}$.

Asimismo, se percibe un acercamiento por parte de los estudiantes a una realidad ajena a la de ellos.

Es reconfortante saber que esperan llevar el curso para realizar las actividades virtuales que tomaron buen tiempo para ser creadas y más aún, que este pueda haber calado en el interés de los alumnos.

- Materiales producidos

Fiesta patronal 1: Huayllán: El corazón de Pomabamba https://youtu.be/WfN_IuvudUc Integrantes: Evelyn Astete, Jorge Benvenuto, Pedro Guerrero y Valeria Pando.

Fiesta patronal 2: Fiesta Patronal de San Francisco de Asis https://youtu.be/e1_OXPrbSZs Integrante: Giancarlo Tomasio.

\subsection{Periodismo de Opinión}

\subsubsection{Cartas al editor}

- Objetivos

Primer objetivo

Revisar y analizar distintas cartas al editor.

Analizar el texto periodístico, identificando la estructura, lenguaje y otras características. Segundo objetivo

Redactar cartas al editor teniendo en cuenta lo identificado en el primer objetivo.

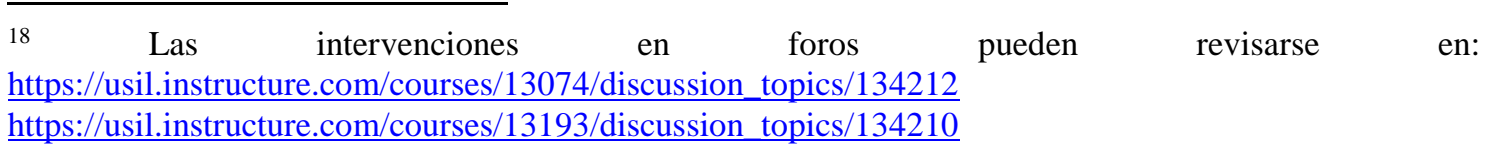


El estudiante debe redactar misivas a distintos medios impresos con la finalidad de que sean publicadas.

\section{Tercer objetivo}

Mantener al estudiante al tanto del contexto actual.

El alumno debe realizar un constante análisis de la coyuntura para poder lograr que sea la carta idónea para el medio y se publique.

\section{- Descripción del caso}

Periodismo de Opinión es un curso de corte teórico-práctico. Lo dicto en la Universidad de San Martín de Porres desde marzo de 2019. El propósito es involucrar a los estudiantes en el ejercicio de la redacción de diferentes subgéneros: editorial, artículo, comentario, cartas al editor, columna, crítica, entre otros. Hacia el final del curso, los estudiantes entregan una compilación de lo producido en el semestre ${ }^{19}$.

He querido traer a colación el ejercicio cartas al editor, en tanto es uno de los pocos que permite una relación instantánea con un medio impreso, puesto que, años atrás, lo hicimos con el profesor Eduardo Lavado para el curso Redacción Periodística. De todas las actividades de esa asignatura, es la que más recuerdo. Es invaluable el hecho de ser estudiante y poder ver tu nombre publicado en una revista que lees desde la niñez.

Ahora, la redacción de las cartas al editor suele responder a varios factores, entre ellos, una respuesta a un hecho noticioso de interés para el medio o bien una reacción a una nota específica publicada con anterioridad. Algunas veces las cartas pueden ensalzar algún artículo del diario o la revista, o muy por el contrario, objetar distintos puntos tratados en ellos. La aceptación de la carta depende, en buena cuenta, de la línea editorial que abrace el medio. Influye también que sea actual, esté bien redactada, sea de interés general, entre otros factores. Para esto, es importante hacer un seguimiento a las cartas y observar su tenor. Otro detalle importante es respetar las reglas solicitadas (cantidad de palabras y datos del remitente). También se hace hincapié en tratar de colocar sentimientos de desconcierto, fastidio, enojo, alegría, etc., para tener mayor certeza de que lo escrito puede constituir un aporte al lector.

${ }^{19}$ Anexos 4: Curso Periodismo de Opinión: compilación de lo producido en el semestre. 
El ejercicio consiste en redactar una carta entre 100 y 150 palabras, respetando los puntos anteriormente mencionados. En caso sea publicada, la calificación recibida anulará la más baja del registro.

Mis principales referencias para teorizar este tema fueron: Periodismo de opinión y Discurso de Susana González (González Reyna, 1991), Periodismo de opinión de Natividad Abril (Abril Vargas, 1999) e Importancia y redacción de la carta al editor (López-Hernández, Brito-Aranda, \& Torres-Fonseca, 2014).

\section{- Resultados obtenidos}

Publicación en medios impresos de las mejores cartas al editor enviadas por los estudiantes (para muchos fue su primera publicación).

El estudiante identifica que tiene voz y voto en los medios de comunicación y que ello conlleva un compromiso ético.

Mejoras en el lenguaje a través de la revisión de diarios peruanos y de textos producidos por sus compañeros.

\section{- Materiales producidos}

Carta al Editor 1: Antonella Montoya

https://1drv.ms/w/s!AvD2xVVJUZAUv0JbGgEWs6snXTG7?e=SX8WCa

Carta al Editor 2: Carlos Prado

https://1drv.ms/w/s!AvD2xVVJUZAUv0HEOyGft70dY78I?e=7AYFMR

Carta al Editor 3: Juan Pablo Salarrayán

https://1drv.ms/w/s!AvD2xVVJUZAUv0R6IfQnNht1LG0t?e=UnUJaI

Carta al Editor 4: Chiara Salinas

https://1drv.ms/w/s!AvD2xVVJUZAUv0NOXz06YSCsoRCg?e=jVpSUt 


\section{III: REFLEXIONES PROFESIONALES}

Mi carrera profesional ha ido por varios caminos. Precisamente, escogí Comunicación por todas las ventanas que me ha ido abriendo a lo largo de los años. Ventanas que me definen como una comunicadora integral en el espacio educativo. Ahora bien, siempre me gustaron las letras. Fue el profesor Antonio González, con el curso de Expresión Escrita, quién me mostró una serie de técnicas que me maravillaron y me enseñaron que era diferente escribir por escribir a contar con una serie de pautas y ejercicios. Con honestidad, debo confesar que no pensé seguirle los pasos. Y bueno, aquí estoy siguiéndolos desde hace varios años, esparciendo mi amor por las letras a través de ejercicios que democraticen la escritura y la hagan querida, como en su momento lo hizo González, actual miembro de la Academia Peruana de la Lengua.

Con un temple totalmente distinto, maestros como Óscar Luna Victoria, Liuba Kogan y Gina Gogin influyeron decididamente en mi acercamiento a temas relacionados con la filosofía, el arte y la sociología. Además, con su ejemplo me mostraron que los docentes podían (y acaso debían) estar al margen de lo políticamente correcto, lejos de cualquier tipo de acartonamiento y solemnidad. A Kogan tuve la suerte de tenerla como profesora en la maestría de la PUCP y que integrara el jurado de la sustentación de mi tesis. Recuerdo como si fuera ayer, las investigaciones que realicé, y ella supo estimular, sobre la vida de los jesuitas o la androginia, el interaccionismo simbólico, entre otras. Hasta ese momento, no había tenido la suerte de conocer a una maestra empoderada, que llevaba el saber con libertad y vivacidad, que nos hacía reflexionar sobre todo aquello que nos rodeaba, de una forma natural y espontánea. Nos pedía tener todos los sentidos alertas para luego teorizar. Mi curso de Comunicación Intercultural intenta seguir su ruta: estar en el campo, observar, vivir y escribir. A su vez, Gogin nos enseñaba muchísimo de eso también en Diseño y Análisis Cualitativo. Diferentes estilos, pero ambas geniales.

Mención aparte merece Óscar Luna Victoria. Diría que fue el "Merlí" de aquellos días. El rebelde de los rebeldes. Sus cursos, Teoría del Conocimiento y Apreciación de Artes Plásticas, me dejaron saber que el pensamiento crítico era un espacio para sentirse augusto (mis días en la prensa estuvieron llenos de crítica). Creo (o quiero creer) que mi 
curso de Periodismo de Opinión lleva mucho de él. De su desparpajo, del ojo analítico y de la libertad de expresión.

Para concluir, deseo hacer mención a Redacción Periodística con Eduardo Lavado. Recuerdo que él era el editor de la revista Somos en aquella época y mi primera carta al editor apareció por esos días en esa publicación. Era parte de los ejercicios de clase y, como ya he relatado, lo repito en mi taller de Periodismo de Opinión. Aunque el Somos de hoy es muy diferente al de entonces, sigue siendo un referente para mis estudiantes. Él me enseñó tres cosas que replico: revisar los textos de todos mis alumnos mientras van redactando, que la práctica es lo principal en este tipo de talleres y que nuestros profesores serán siempre los primeros contactos con oportunidades laborales. Con Lavado constaté una vez más que escribir es un espacio seguro.

Ahora bien, para todos aquellos que deseen dedicarse a la maravillosa labor de la docencia, quisiera hacer algunas reflexiones finales:

\subsection{Sobre mi método de trabajo}

Desarrollar una clase conlleva una extensa preparación previa. Cada semana propuesta en el sílabo requiere revisar mucho material para extraer todo aquello que calce con el tema e iniciar la planificación semanal. Las clases tienen un logro de sesión que está alineado al temario. Asimismo, tres fases -contextualización, construcción y cierrey por cada una de ellas, la estrategia, el “¿cómo vamos a lograr esto?”. Planificar no es una tarea sencilla. Hay que proyectarse en el futuro y pensar si lo que estamos estructurando calzará con nuestros estudiantes. Asimismo, hay que considerar que cada sesión es variable y debe tener un margen de cambio acorde al ritmo de los alumnos. Luego, la concepción debe materializarse y se pueden empezar a crear apoyos audiovisuales (PPT, Prezi, Pow Toon, etc.), a preparar la dinámica de clase siguiendo algún método de enseñanza (Flipped Classroom, Design Thinking o Proyectos) y formas de evaluación (por pares, autoevaluación, etc.). Más allá de todo esto, es menester definir dos puntos más: decidir el tono de la clase -factor variable- y cuáles son las habilidades blandas que buscamos desarrollar colateralmente. 


\subsection{Ellos son los protagonistas en el aula invertida}

Practico el modelo de aprendizaje Flipped Classroom. La posibilidad de que mis estudiantes tomen el control de la clase, dejándolos crear en libertad, explorando, haciendo consultas, analizando ideas y debatiéndolas, me parece maravilloso. En definitiva, continúo trabajando en cómo perfeccionar la afectividad y la eficacia docente, temas que me apasionan. No cabe duda que mi fortaleza siempre ha sido el aula, el contacto con los estudiantes: dejarles sentir que, más allá del entorno, es posible desarrollar afectos para que el proceso sea eficaz. Recalco, sigo trabajando en ello.

Ahora bien, coincido en que la figura "emisor-profesor" y "receptor-alumno", como los modelos que ayer permitían explicar el proceso comunicativo, hoy exhiben evidentes limitaciones (Islas Carmona, 2008). A veces percibo un alumnado cada vez más pasivo e incluso renuente en las primeras sesiones. Aquí es donde entra a tallar el perfil de comunicador. En ese sentido, el aporte que puedo dar se sustenta en el conocimiento académico y la experiencia de campo. Ambos me permiten brindar a los alumnos un aprendizaje basado en la realidad. A partir de ello, se generan mensajes que puedan conectar con las audiencias, a través de la razón y la emoción. La docencia universitaria, como toda actividad que implica interacción humana, requiere sin duda de la comunicación. En ese sentido, el aporte de un comunicador es fundamental en el proceso pedagógico, toda vez que aporta el manejo no solo de la comunicación verbal sino también de la no verbal. El ejercicio de la docencia implica la capacidad de transmitir contenidos a veces complejos, y a la vez demanda contar con habilidades blandas para captar el interés del alumnado. Por todo ello, la comunicación es esencial.

\subsection{Nosotros como docentes frente a las TIC}

Es necesario un cambio de rol en las concepciones originales de la dupla docente/estudiante. Se debe puntualizar que "la tecnología por sí sola no guía” (Viñals \& Cuenca, 2016). Hoy más que nunca el profesor debe actuar como un acompañante constante del alumno en este nuevo proceso de aprendizaje.

Es innegable reconocer que todo va a la par de los avances tecnológicos. La educación no puede ni debe ser ajena a ellos. Gracias a ello, considero que se puede lograr la tan ansiada descentralización del espacio físico educacional. Lo cual podría constituir 
una solución frente a la excesiva cantidad de estudiantes por aula en algunas universidades, al tiempo prolongado que ellos pasan trasladándose (en pro de su salud mental), a la posibilidad de reforzar el aprendizaje autónomo con miras a desarrollar otro tipo de soft skills más acordes con el tiempo actual.

\subsection{Consejos para los futuros comunicadores}

Solo algunas apreciaciones, sea que vayan a dedicarse a lo docencia, al periodismo, las relaciones públicas o la comunicación empresarial.

Sientan todo en las entrañas. Produzcan desde adentro, desde las vísceras, con mucha pasión, con todo a flor de piel. Cueste lo que cueste.

También repito otro consejo que en su momento me dio el profesor Luna Victoria: "Bustamante, estudia por lo menos dos idiomas. Te meterás el mundo al bolsillo. Y guarda todos los trabajos que realices en la carrera. Todo te servirá más adelante”.

Además de ello, practiquen desde los primeros ciclos. Involúcrense en la vida universitaria. Participen en eventos académicos - la experiencia que gané al lado del profesor Jorge Cornejo Polar apoyando en sus congresos de literatura fue invaluable-. Dialoguen con sus profesores favoritos, pídanles consejo. También viajen y conozcan las experiencias de las personas que encuentren en su camino. Lean, vayan al cine, vuelvan a leer. Desarrollen sus habilidades blandas. Sin ellas, el mundo se tornará doblemente complicado. 


\section{TEXTOS RECOMENDADOS}

ANDERSON, Perry. 1998. "The origins of Postmodernity” [en línea].

ARFUCH, Leonor. 2002. "El espacio biográfico. Dilemas de la subjetividad contemporánea". Buenos Aires: Fondo de Cultura Económica.

BAUMAN, Zygmunt. 2002. Modernidad líquida

BERMAN, Marshall. 1989. “Todo lo sólido se desvanece en el aire” [en línea].

DELEUZE Gilles y Félix GUATTARI. 2003. "Rhizome” [en línea].

FOUCAULT, Michel. 1998. "Vigilar y Castigar: Nacimiento de la prisión” [en línea]. HARAWAY, Donna. 1995. "Ciencia, cyborg y mujeres. La reinvención de la naturaleza".

LIPOVETSKY, Gilles. "La era del vacío: ensayo sobre el individualismo contemporáneo".

LIPOVETSKY, Gilles. "El imperio de lo efímero: La moda y su destino en las sociedades modernas". 


\section{BIBLIOGRAFÍA}

Abril Vargas, N. (1999). Periodismo de opinión: claves de la retórica periodística. Madrid: Síntesis.

Aguilera-Ruiz, C., Manzana-León, A., Martínez-Moreno, I., Lozano Segura, M. d., \& Casiano Yanicelli, C. (1 de Abril de 2017). Redalyc. Recuperado el 10 de Febrero de 2020, de https://www.redalyc.org/pdf/3498/349853537027.pdf

Barletta, F., Pereira, M., Robert, V., \& Yoguel, G. (2013). Argentina: dinámica reciente del sector de software y servicios informáticos. Revista de la CEPAL(110), 137155.

Obtenido

de http://www.cepal.org/publicaciones/xml/1/50511/RVE110Yoqueletal.pdf

Calvi del Risco, J. A. (2015). Revista Latinoamericana de Derecho y Religión. Obtenido de 2.4.6/index.php/RLDR/article/view/6

http://www.revistalatderechoyreligion.com/ojs/ojs-

Chojín, E. (Abril de 2011). YouTube. Recuperado el 2018, de https://youtu.be/Z18W6ddWfM8

Chojín, E., \& Enece, P. (2018). YouTube. Obtenido de https://youtu.be/4DjO43XG72c

Choy, M., \& Chang, G. (2014). Medidas macroprudenciales aplicadas en el Perú. Lima: Banco Central de Reserva del Perú. Obtenido de http://www.bcrp.gob.pe/docs/Publicaciones/Documentos-deTrabajo/2014/documento-de-trabajo-07-2014.pdf

García Nieto, J. P. (2013). Consturye tu Web comercial: de la idea al negocio. Madrid: RA-MA.

García, J. J., \& Tacuri, K. (Agosto de 2006). FLACSO. Obtenido de https://biblio.flacsoandes.edu.ec/libros/digital/52991.pdf

Goldoni, C. (1996). Dialnet. Recuperado el 2020, de https://dialnet.unirioja.es/servlet/articulo?codigo $=4792215$

González Reyna, S. (1991). Géneros periodísticos 1: periodismo de opinión y discurso. México D.F.: Trillas.

Islas Carmona, J. O. (Junio de 2008). Scielo. Recuperado el 12 de 2 de 2020, de http://www.scielo.org.co/pdf/pacla/v11n1/v11n01a03.pdf

López García, J. C. (2018). Eduteka. Recuperado el 3 de Febrero de 2020, de https://eduteka.icesi.edu.co/modulos/8/247/889/1

López-Hernández, D., Brito-Aranda, L., \& Torres-Fonseca, A. (2014). Redalyc. Obtenido de https://www.redalyc.org/pdf/473/47333055011.pdf 
Miguel, J. (Marzo de 2017). Diario El Comercio. Obtenido de https://elcomercio.pe/blog/librosami/2017/03/catalina-romero-los-grupos-quese-cierran-corren-riesgo-de-desaparecer/

Pérez-Bustamante Mourier, A. S. (2005). Microrrelato: Grandes placeres de la pequeña literatura. Salina Revista de Letras. Obtenido de https://rodin.uca.es/xmlui/bitstream/handle/10498/16253/MICRORRELATOS\% 20\%28GRANDES\%20PLACERES\%20DE\%20LA\%20PEQUENA\%20LITER ATURA\%29.pdf? sequence $=1 \&$ isAllowed $=\mathrm{y}$

Perezchica, E. (2008). Literatura Libre. Obtenido de https://www.canalliteratura.com/Libros/antologia-cadaver-exquisito-literatura-libre\%5B1\%5D.pdf

Revistas de la Universidad Nacional Autónoma de México. (2015). Obtenido de http://www.revistas.unam.mx/index.php/eutopia/article/view/53535/47592

Salas

Díaz,

M.

(2011).

Dialnet.

Obtenido

de https://dialnet.unirioja.es/servlet/extaut?codigo=1983339

Sánchez Cruzado, C. (2017). Repositorio de Tesis de la Universidad de Málaga. Recuperado el 28 de Enero de 2020, de https://riuma.uma.es/xmlui/bitstream/handle/10630/14993/TD_SANCHEZ_CR UZADO_Cristina.pdf?seq

Sicilia, A. (1999). Researchgate. Recuperado el 2020, de http://www.researchgate.net/publication/234680658

Silva Salgado, M. F. (2016). Academia. Recuperado el 2019, de https://www.academia.edu/33758514/La_universidad_de_la_calle_y_de_la_vid a._El_Hip_Hop_como_experiencia_educativa..pdf

Telefónica, F. (2012). Fundación Telefónica. Recuperado el 2019, de https://www.fundaciontelefonica.com/noticias/17_01_2014_esp_6370-2990/

Viñals, A., \& Cuenca, J. (Agosto de 2016). Redalyc. Recuperado el 5 de Febrero de 2020, de https://www.redalyc.org/pdf/274/27447325008.pdf

Wittmann, R. (2006). ¿Hubo una revolución en la lectura a finales del siglo XVIII? En G. Cavallo, \& R. Chartier, Historia de la lectura en el mundo occidental (págs. 435-472). México D.F.: Santillana. 


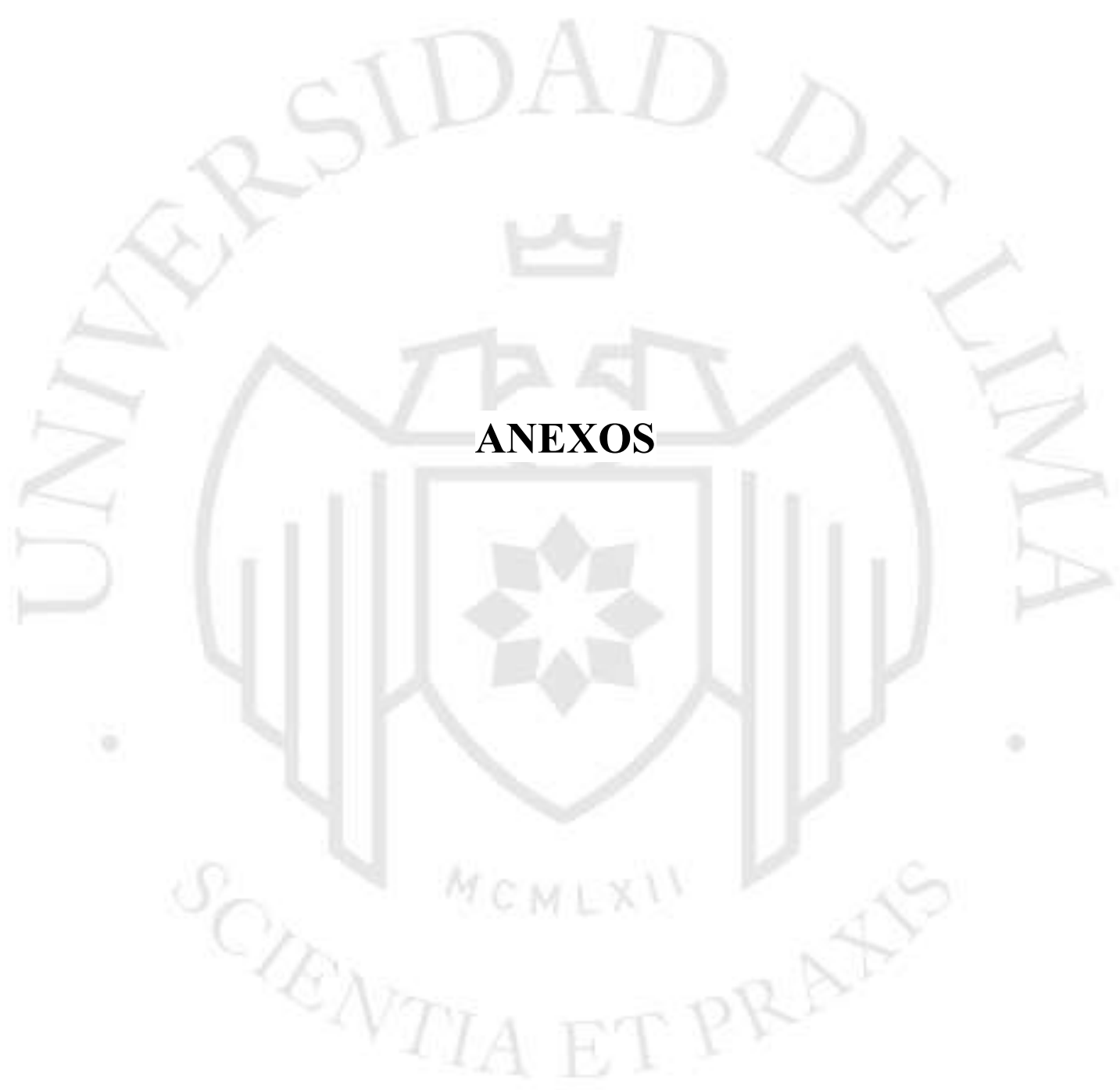




\section{Anexo 1: Portada e índice del libro: Comunicación y Cambio}
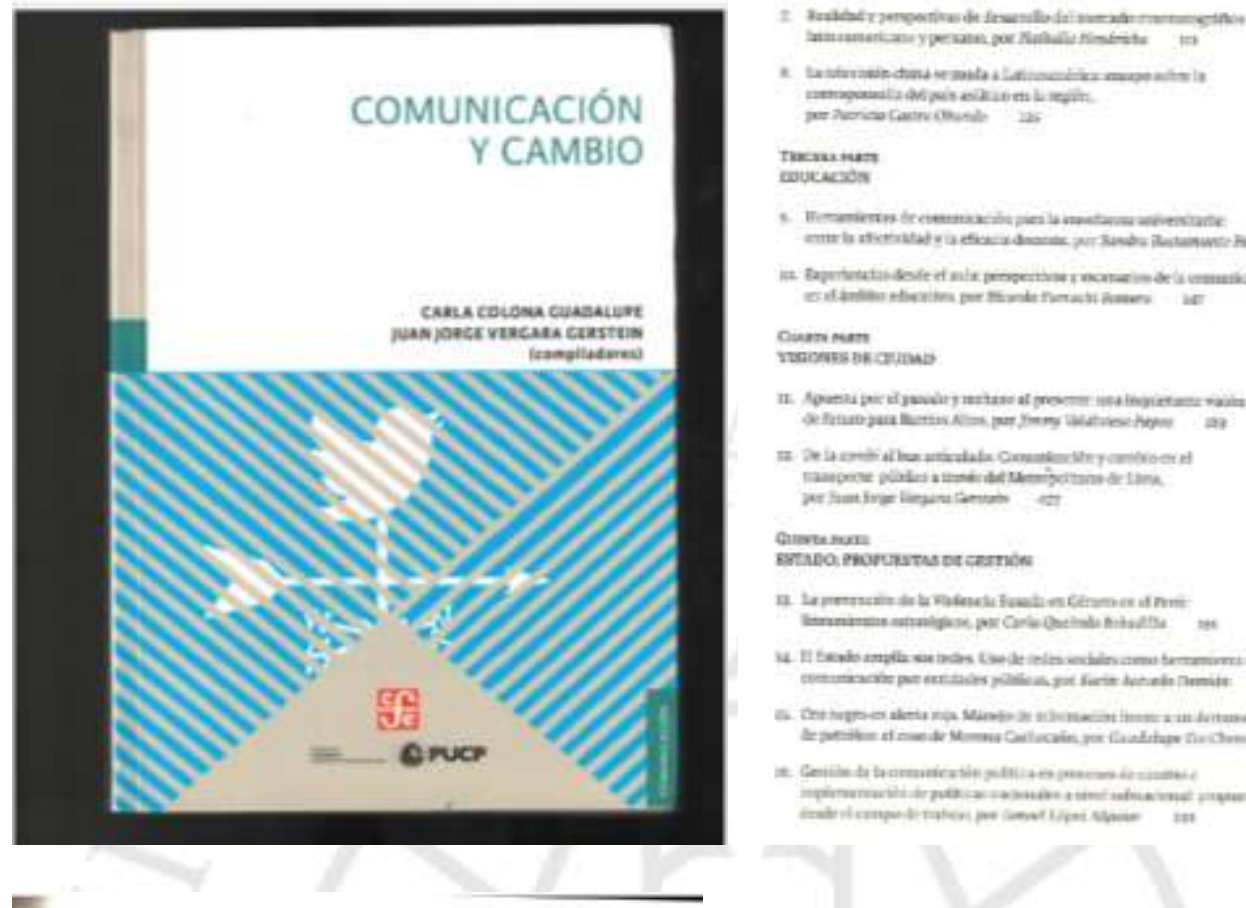

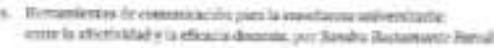

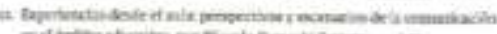

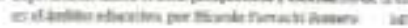

Ciemman

vascous akcamas

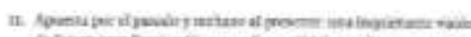

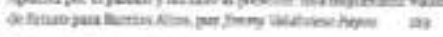

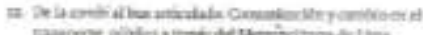

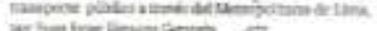

Givanum

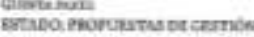

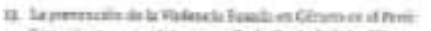

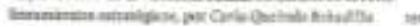

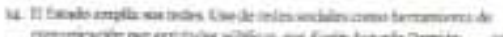

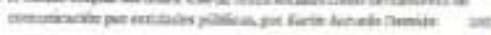

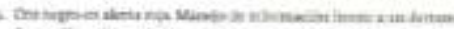

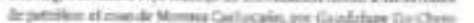

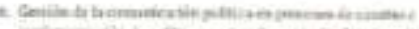

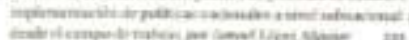

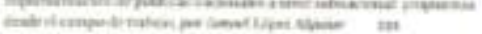

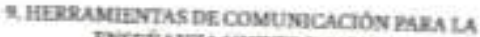
DNSENANCZ UNIVFESTTARIA: ENTBELLAFCTIVTM Y LA EHCNCA DOCENTE

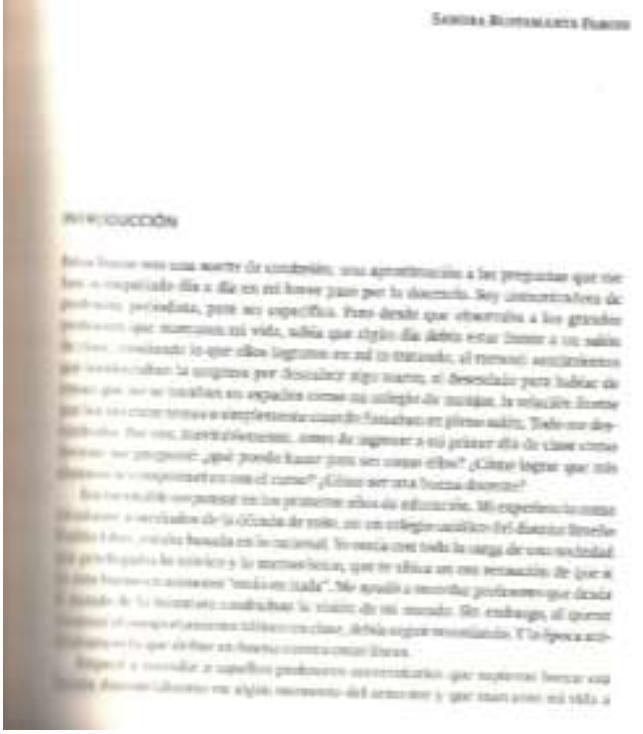




\section{Anexo 2: Textos periodísticos: diario Expreso y revista}

\section{Sommelier}

Diario Expreso (2002-2005)

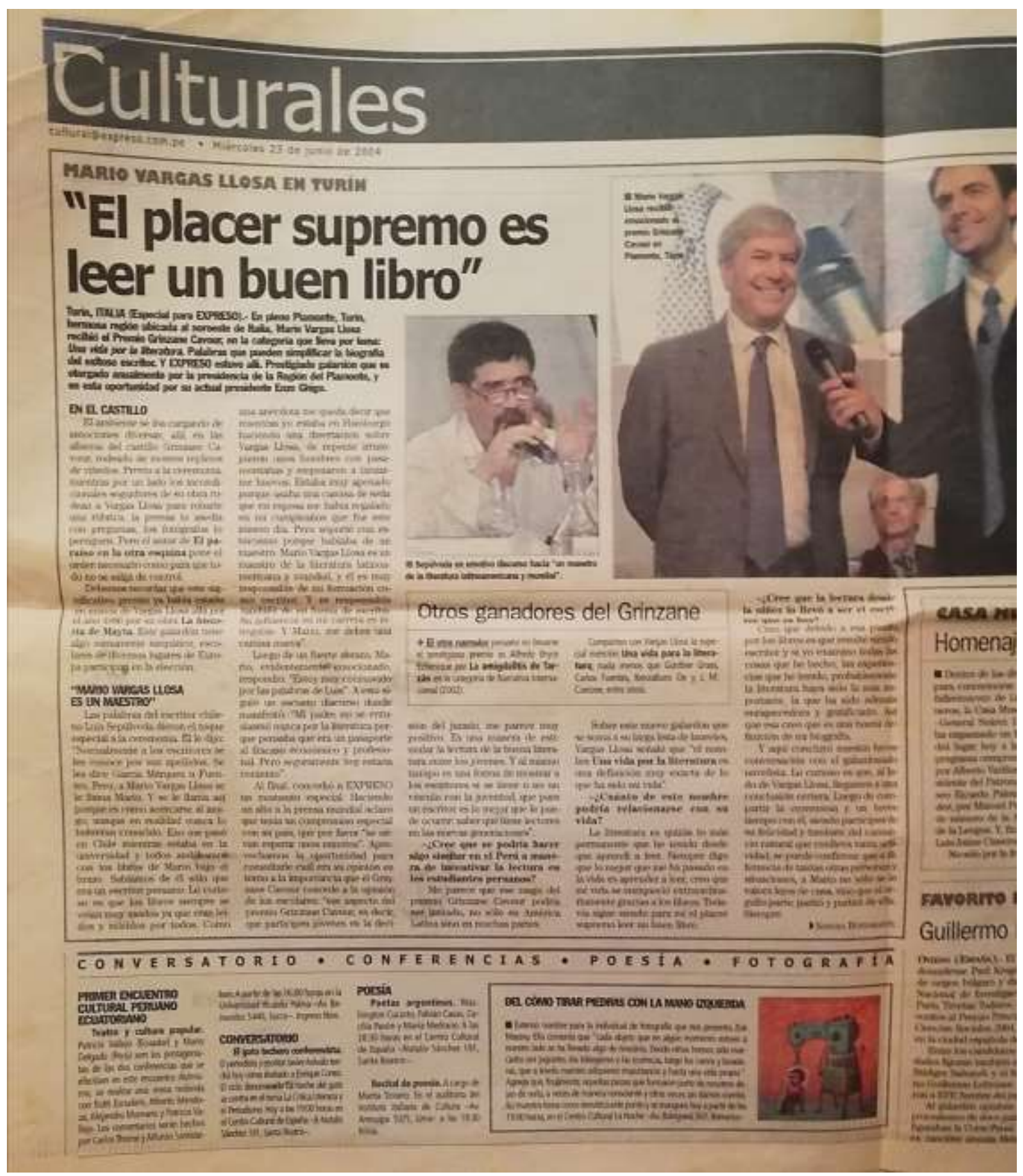




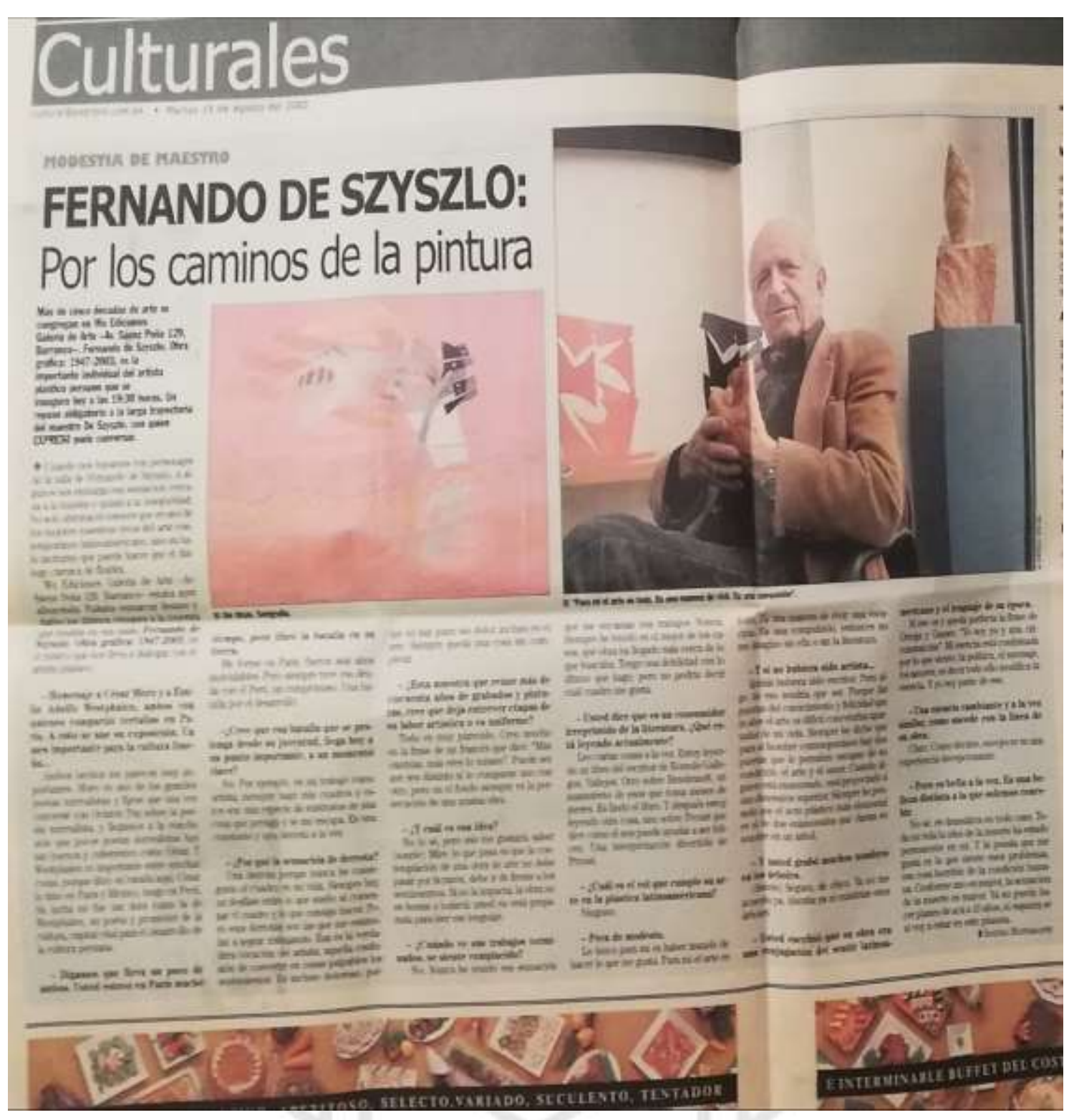




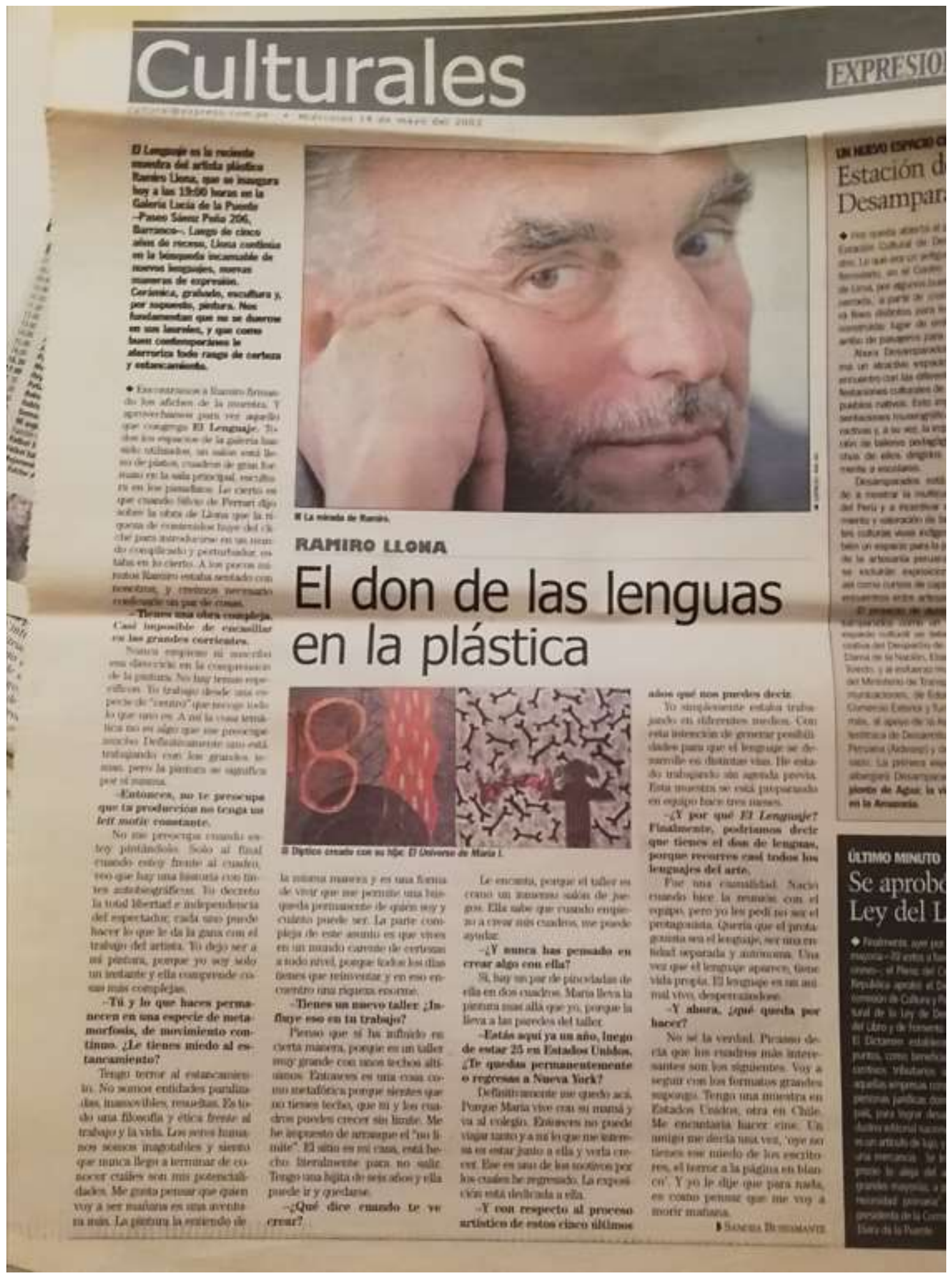




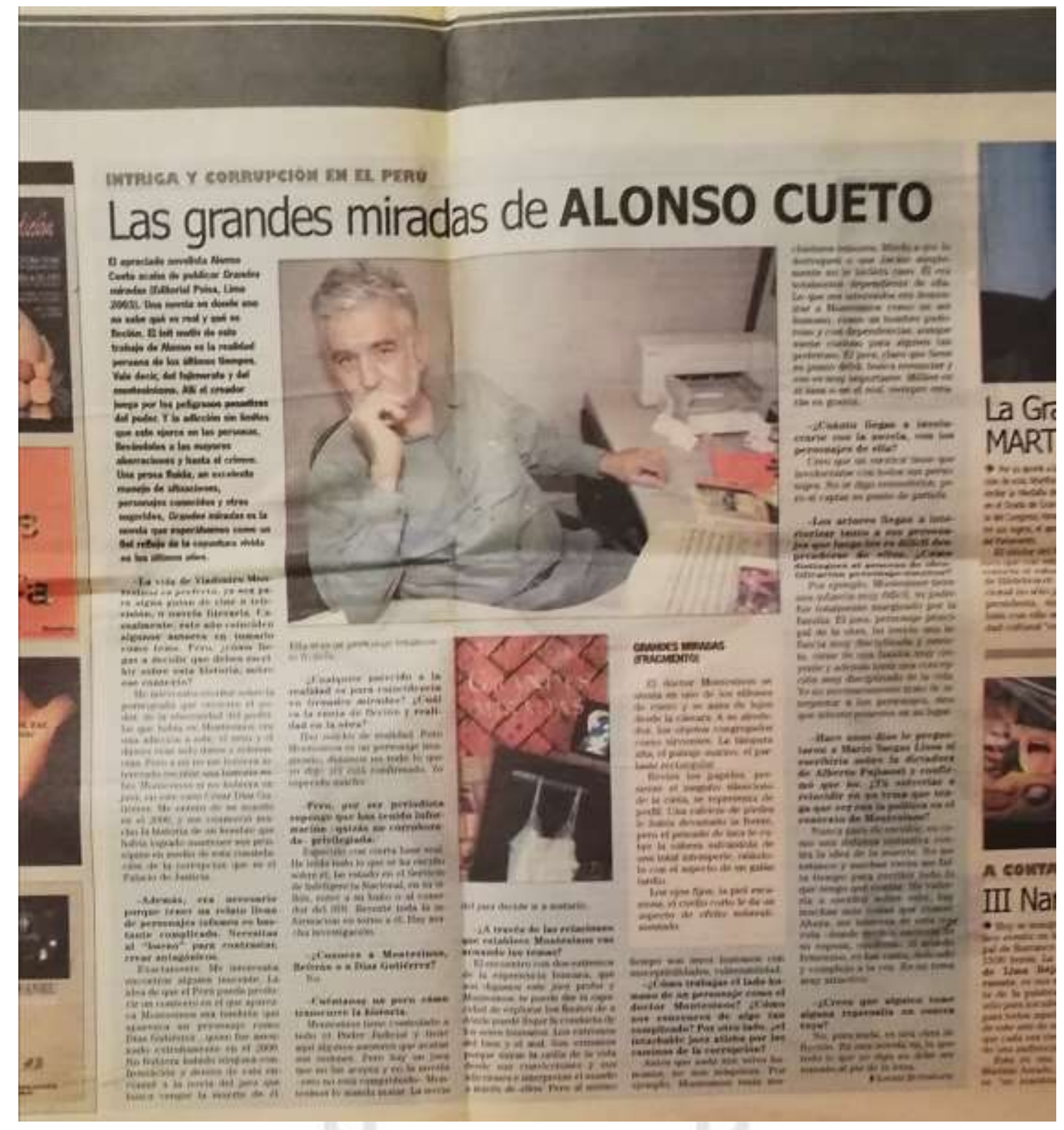




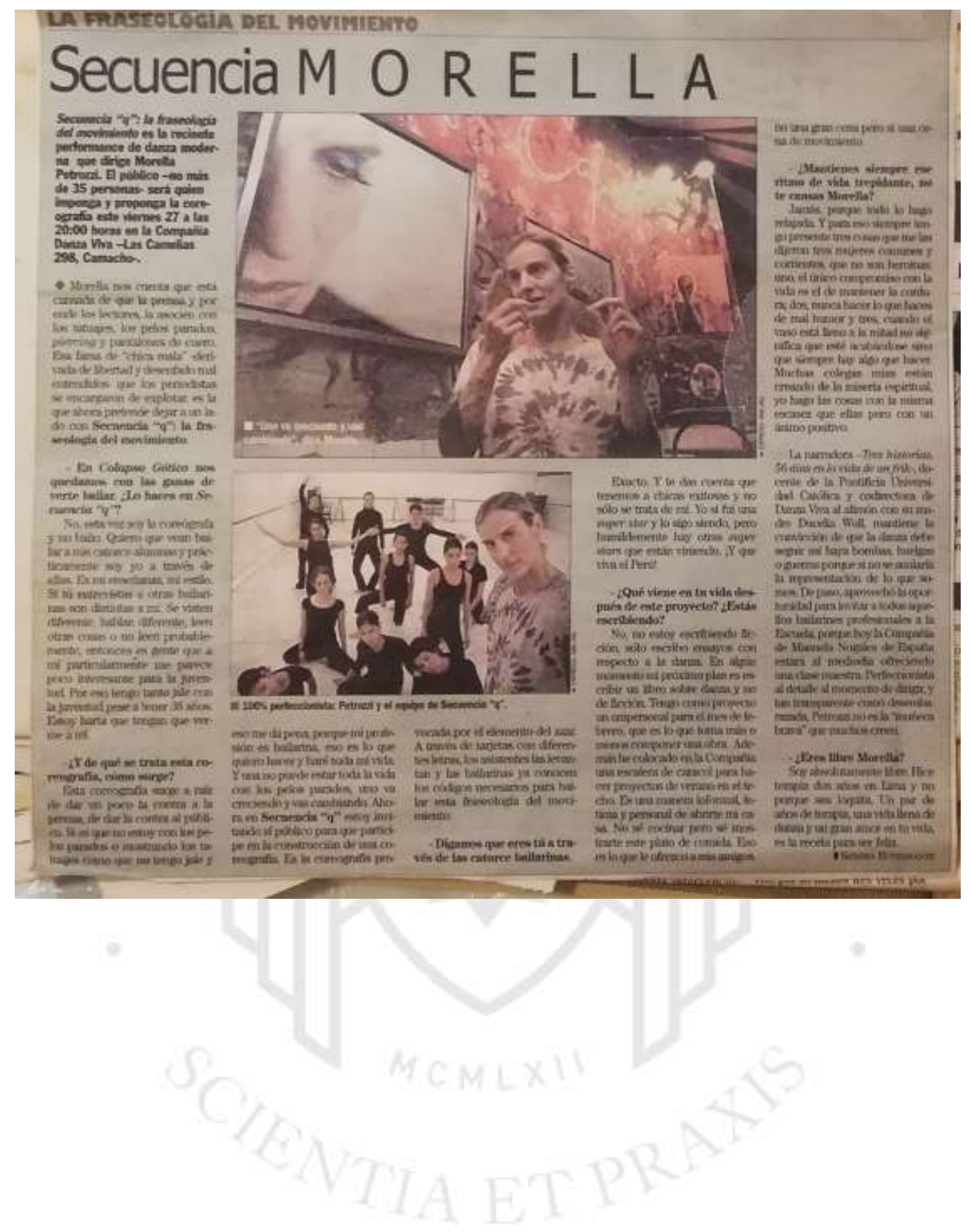




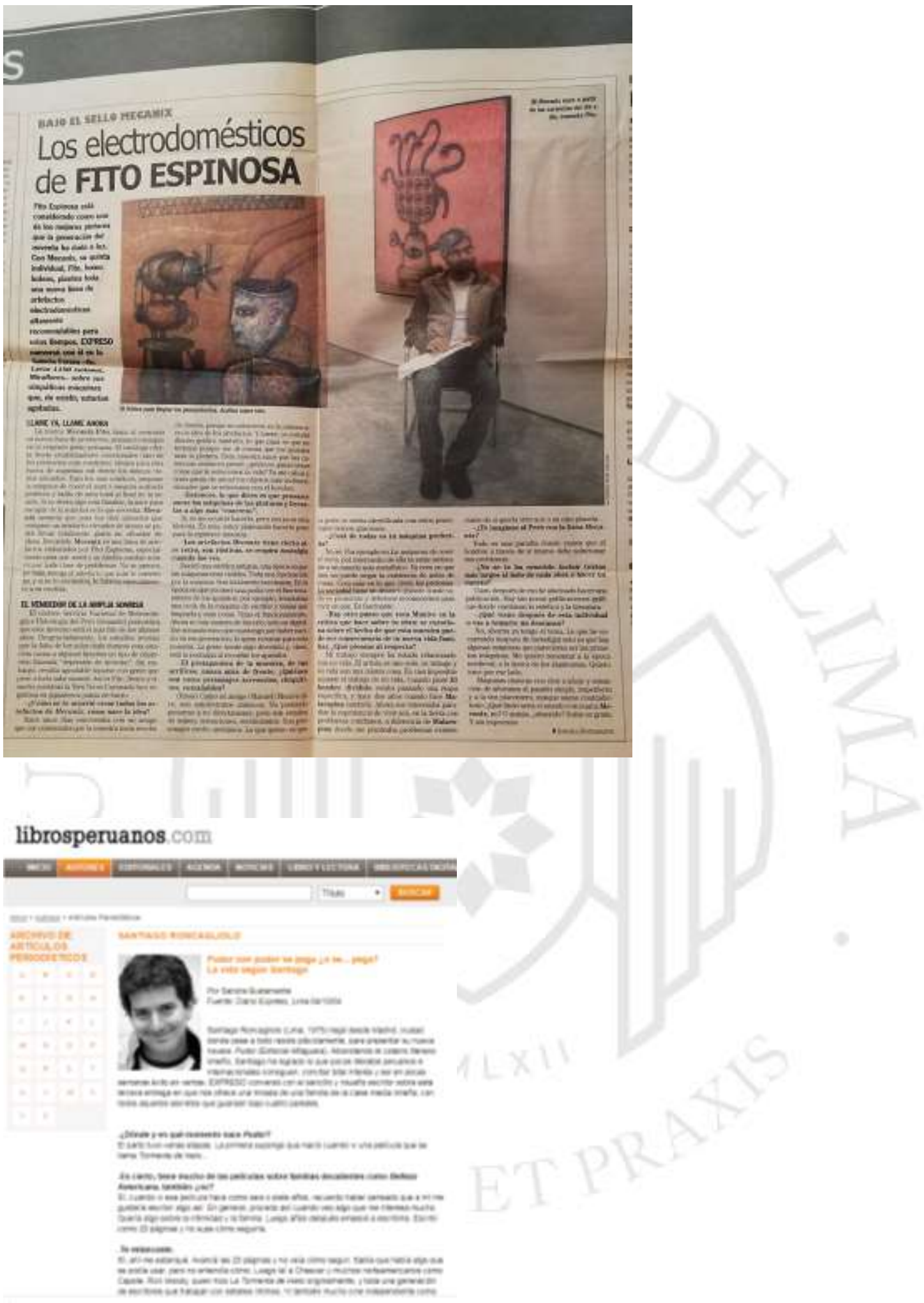

http://www.librosperuanos.com/autores/articulo/00000001020/Pudor-con-pudor-sepaga-o-se...-pegaLa-vida-segun-Santiago 
Revista Sommelier (fragmentos / 2009-2010)

Textos completos:

https://1drv.ms/u/s!AvD2xVVJUZAUwA2gP4PmGovXK3IE?e=pFUNfu
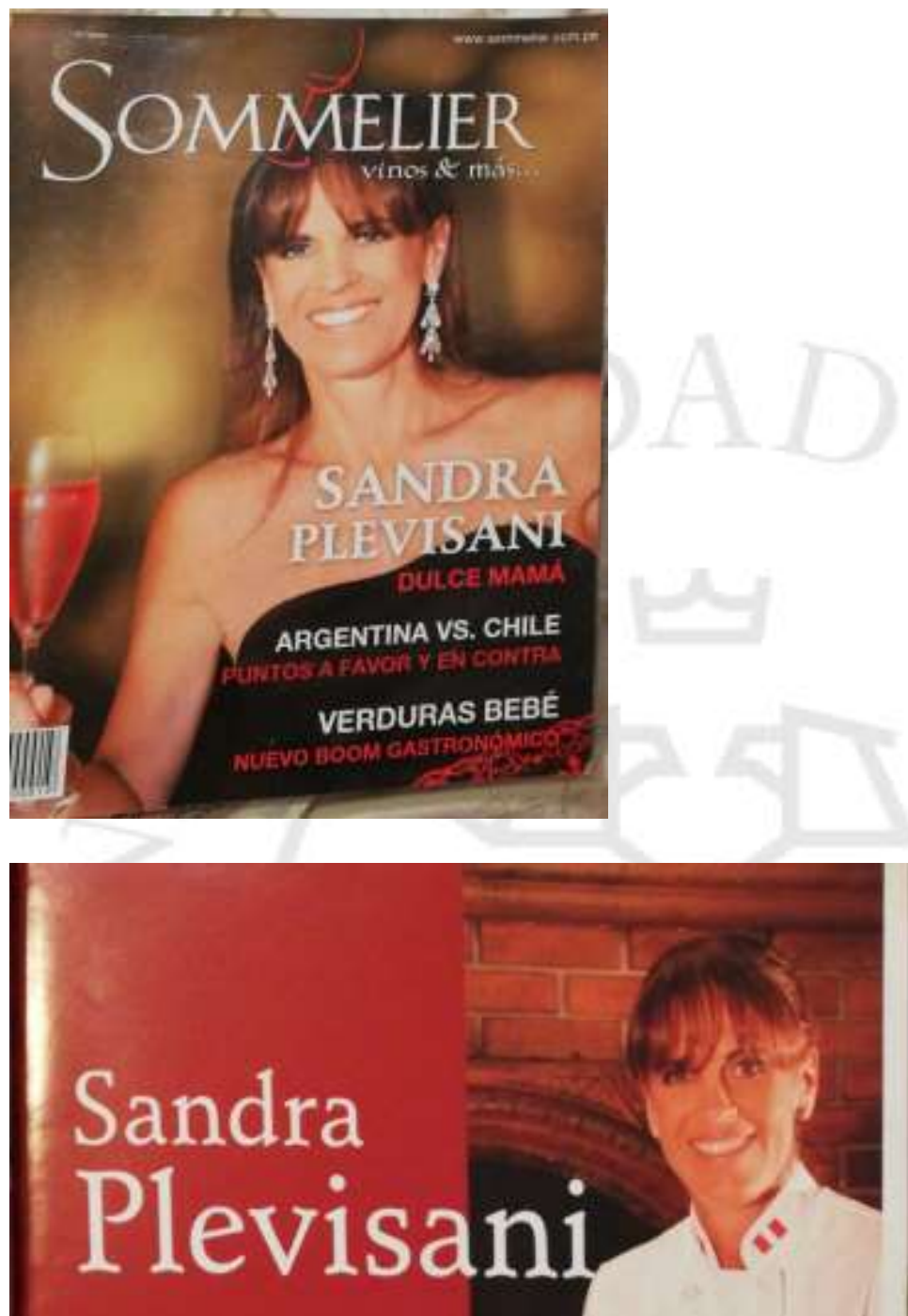

Sanope ven case da a mil por hore

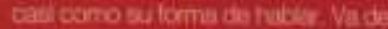

yes of ane trateras a che cmis.

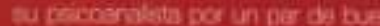

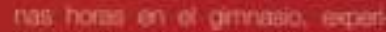

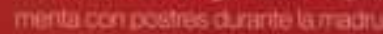

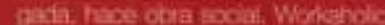

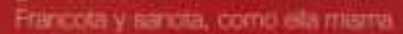
dion come in crocolath cada din

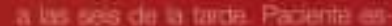
pose. Pero sactie todat gat conas os mani do as aye bon deve y cresenosiss os has bye cuidm y

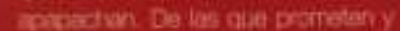
cultorin con craces

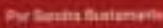
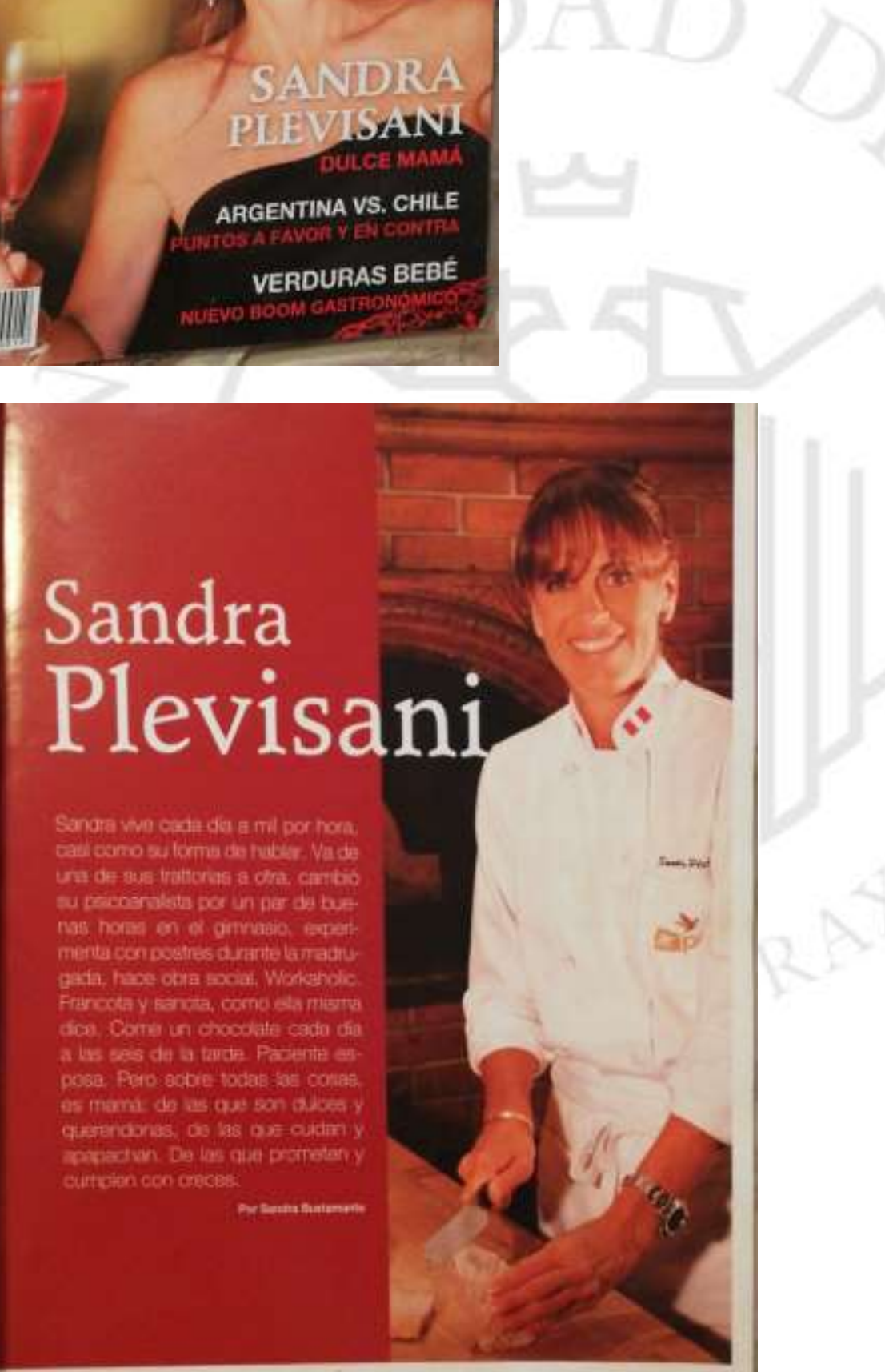


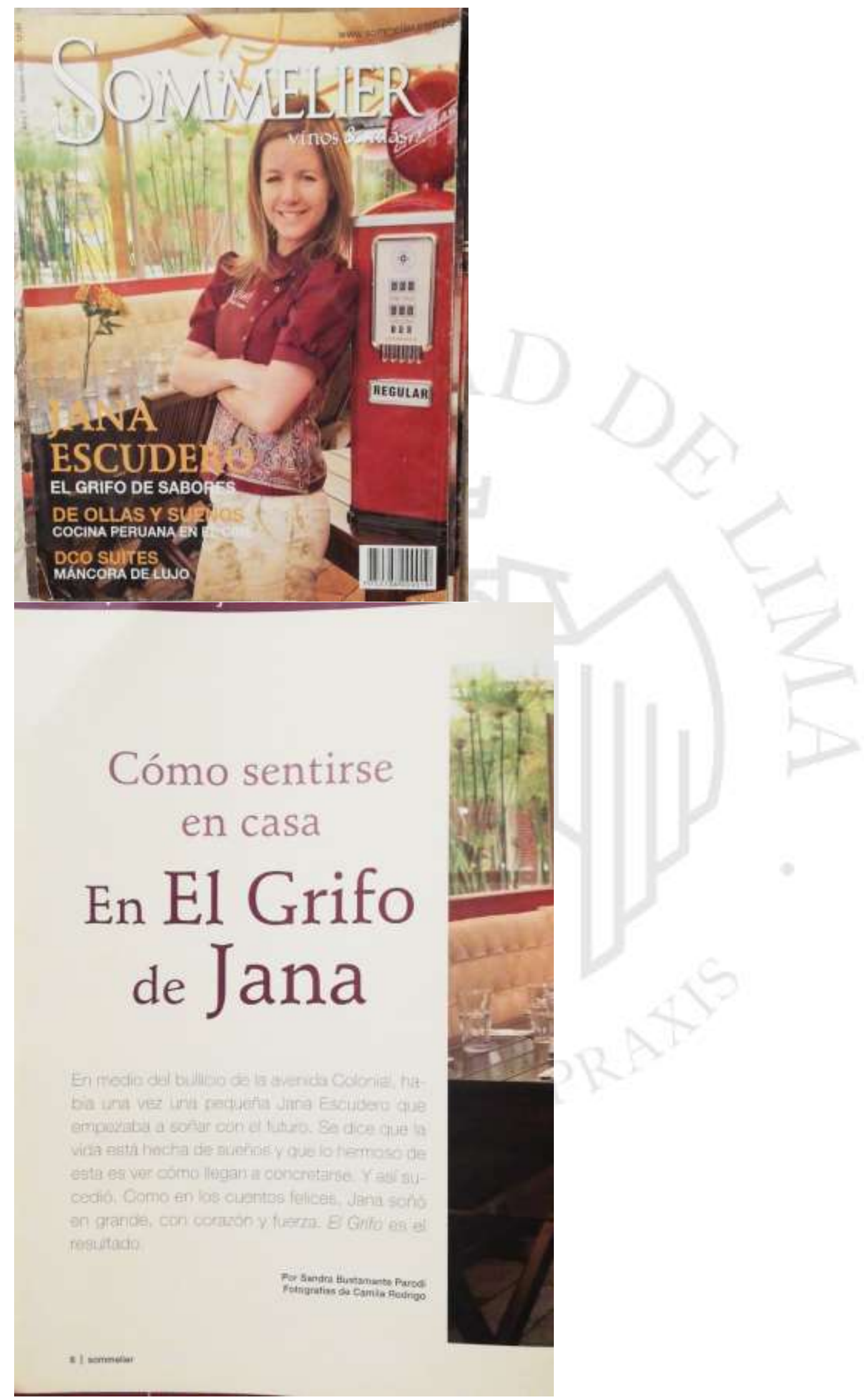



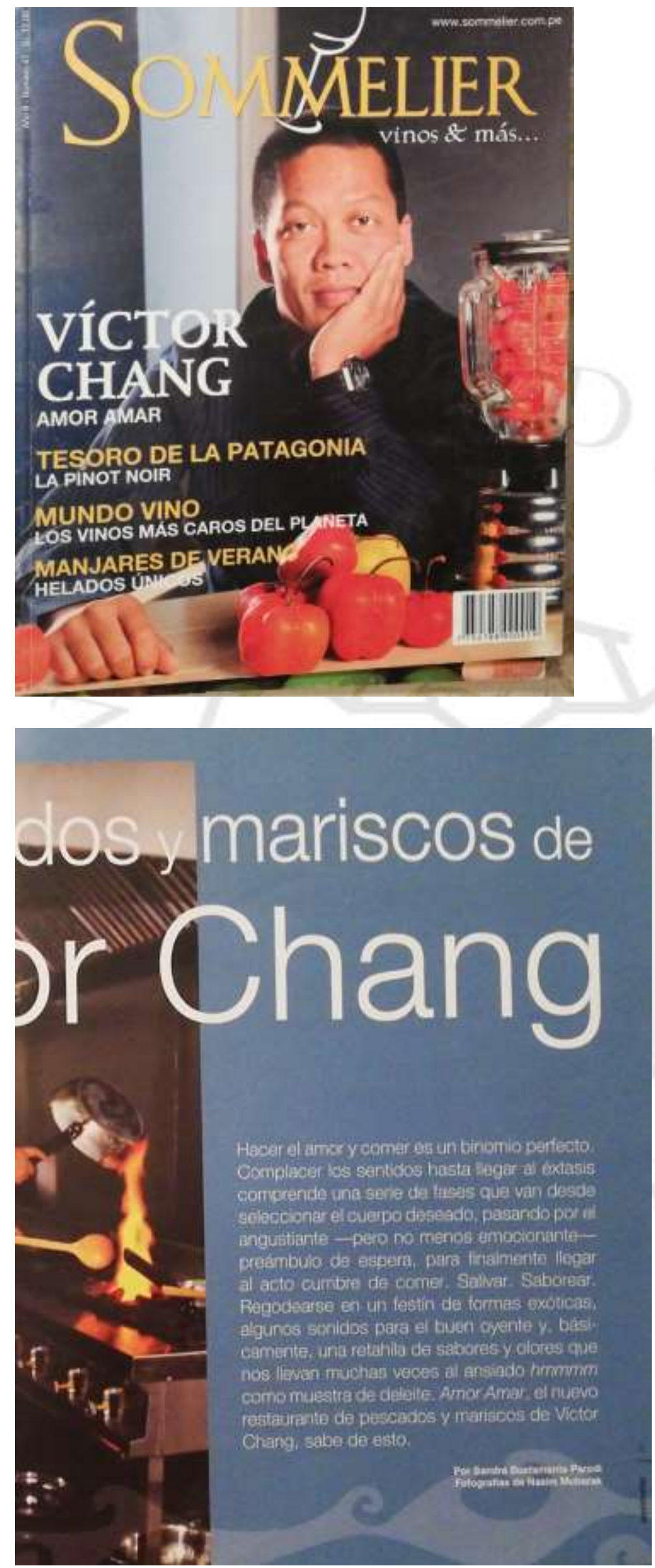


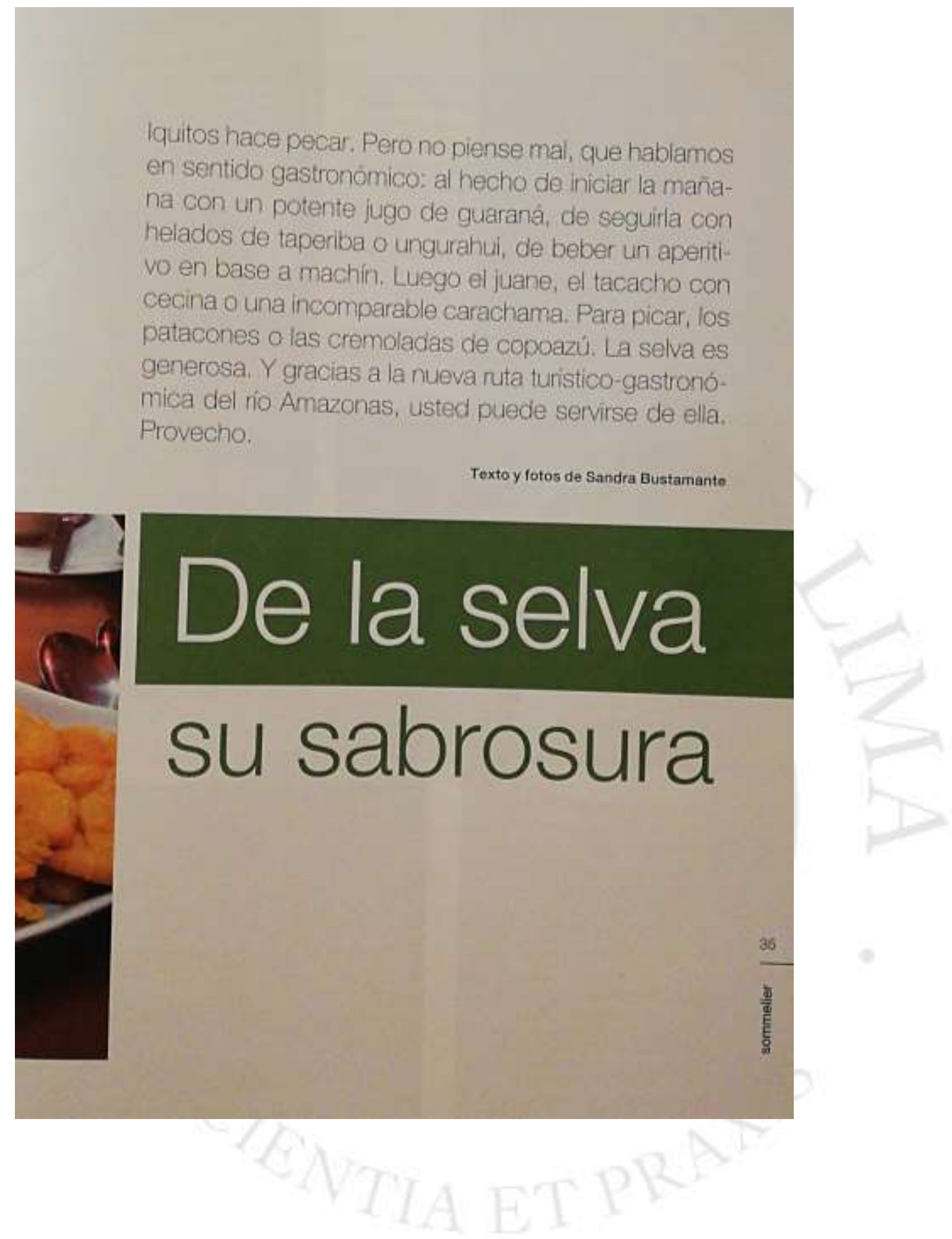




\section{Anexo 3: Listado general de capacitaciones, cursos, diplomado, entre otros}

\section{CAPACITACIONES}

2020

Webinar Cómo implementar una estrategia de originalidad en educación virtual - Turnitin Latinoamérica https://1drv.ms/b/s!AvD2xVVJUZAUv2Tm9X941QdFpapw?e=yQHB9X

2019

Seminario Taller de Didáctica y Evaluación Basados en el Enfoque por Competencias - Universidad de San Martín de Porres https://1drv.ms/b/s!AvD2xVVJUZAUwC3oymGhJFLVojqK?e=6JjHuj

Capacitación virtual: Autocuidado y salud en el trabajo - Universidad de San Martín de Porres https://1drv.ms/u/s!AvD2xVVJUZAUwAQixs4r3_2fNv8B?e=LIengi

III Coloquio Internacional de Investigación en Comunicación en la Era Digital Universidad Austral de Chile/Universidad San Ignacio de Loyola (Mayo) https://1drv.ms/b/s!AvD2xVVJUZAUwAIJJYdXgoU7ELFW?e=Pc6X8R

Diplomado Semipresencial en TIC aplicadas a la Educación https://1drv.ms/b/s!AvD2xVVJUZAUwAF1I23Bugx6fgP0?e=xUb4KT

2018

Curso de Inducción Docente en el Enfoque USIL de Formación por Competencias - Universidad San Ignacio de Loyola https://1drv.ms/b/s!AvD2xVVJUZAUv3uTwtDBaMD8ocW1?e=pgbIFC

II Coloquio Internacional de Investigación en Comunicación en la Era Digital USIL/Universidad de la Costa https://1drv.ms/u/s!AvD2xVVJUZAUv3nCibP45RHlHr43?e=oJfChp

Webinar Acciones para formar y transformar estudiantes íntegros - Turnitin Latinoamérica https://1drv.ms/w/s!AvD2xVVJUZAUv3zBfFYMyw18Osd_?e=Ytd7NY

Estilos de aprendizaje ¿cómo aprenden los estudiantes universitarios? https://1drv.ms/b/s!AvD2xVVJUZAUv3qBmwr7D5Ahdkor?e=1d1j11 
Loyola

Curso: Diseño de instrumentos de medición - Universidad San Ignacio de

https://1drv.ms/u/s!AvD2xVVJUZAUv3MZJZKsIQ831x4E?e=zc97zY

Curso: Proyecto de investigación - Universidad San Ignacio de Loyola https://1drv.ms/u/s!AvD2xVVJUZAUv3hVQG9xrKBdZKLX?e=uqDccE

Curso: Búsqueda sistemática de información y evidencias - Universidad San Ignacio de Loyola https://1drv.ms/u/s!AvD2xVVJUZAUv3DsL7kw6G4pjyAI?e=Gf51TY

III Conferencia de Calidad Académica: Retos y Perspectivas para el trabajo del Docente Universitario - Universidad San Ignacio de Loyola https://1drv.ms/u/s!AvD2xVVJUZAUv3KfZHAI6uWOy7wL?e=5bdnNM

2016

Curso: Creación de páginas web para fines académicos https://1drv.ms/u/s!AvD2xVVJUZAUv23qg_FMkCBrFiWZ?e=STYjXg PUCP

Curso: PCI Líderes Curso Gestión de Procesos e Indicadores - CENTRUM https://1drv.ms/u/s!AvD2xVVJUZAUv2wdw9hLF3ZX23ZM?e=1B47er

Curso: PCI Líderes Taller de Gestión Emocional aplicada a la gestión de equipos - CENTRUM PUCP https://1drv.ms/u/s!AvD2xVVJUZAUv2vQX2A9f-1n9qq-?e=eXhrRZ

Curso: Diseño y elaboración de presentaciones audiovisuales para la enseñanza https://1drv.ms/u/s!AvD2xVVJUZAUv28ImTr-Iu9nJOV8?e=Z8VwC6

2015

Curso: Programa para ejecutivos - CENTRUM PUCP

https://1drv.ms/u/s!AvD2xVVJUZAUv2jaE0Lqpp5D9NnG?e=bbMXIR

Curso: Herramientas de Comunicación para la Docencia - USIL https://1drv.ms/u/s!AvD2xVVJUZAUv2n8N_r5p54Lqnkz?e=wxolAR

Seminario Internacional: ¿Cómo negociar con gente difícil? https://1drv.ms/u/s!AvD2xVVJUZAUwC6199yGF7742mtB?e=sVWrR4

Seminario de Social Media y el poder del cliente - PUCP https://1drv.ms/u/s!AvD2xVVJUZAUv2rIkgwhjOCuYf2q?e=PXGbKy

2014

Curso: Elaboración de Rúbricas - USIL https://1drv.ms/u/s!AvD2xVVJUZAUv2dFfhSGQR7VuFcq?e=QdeNno 


\section{PONENCIAS}

2016

Ponente en el Congreso Internacional Estudios Generales: Globalización e Interculturalidad

https://1drv.ms/u/s!AvD2xVVJUZAUv27ups1uR-0OoHHI?e=WEgLtL

2011

Ponente en el "Taller para periodistas y comunicadores para incorporar acciones de incidencia contra la violencia familiar dentro de su rol comunicacional" https://1drv.ms/u/s!AvD2xVVJUZAUv2X8dTf89aM07HzI?e=5vuw7a

EVALUACIÓN

FONDECYT: Evaluación externa del concurso: Programa de Diplomado en Divulgación Científica 2019-01

https://1drv.ms/b/s!AvD2xVVJUZAUwACIlBRVQGHuLKa5?e=qcwC8d

DISTINCIONES Y PREMIOS

Mejor docente carrera de Comunicaciones Universidad San Ignacio de Loyola https://1drv.ms/u/s!AvD2xVVJUZAUv3_qyryLgmCNIClz?e=4gClYm

Segundo lugar en la Hackaton organizada por The Blockchain Challenge https://1drv.ms/u/s!AvD2xVVJUZAUv311LIy3tv55VyQF?e=HpGow1 


\section{Anexo 4: Curso Periodismo de Opinión: compilación de lo producido en el semestre}

1. Cuatro letras: https://bit.ly/381NZCB

2. Nuestra voz: https://bit.ly/365Y7Zd

3. Raíces: https://bit.ly/2DGUjkW

4. Contracultura: https://bit.ly/37ZErId

5. La provincia: https://bit.ly/2LlQi9O

6. Traficando escritos: https://bit.ly/33MOtZT

7. El actual: https://bit.ly/2RkBqwe

8. Nueva élite: https://bit.ly/2YfDs21

9. Los opinólogos: https://bit.ly/2RpXyVI

10. Con voz y voto: https://bit.ly/2PaUkml

11. Somos comunicadores: https://bit.ly/2ORrxod 